\title{
Glitch-Visible Cities - Fictional Essays
}

by

Freed Gomes

A thesis submitted to the Faculty of Graduate and Postdoctoral Affairs in partial fulfillment of the requirements for the degree of

Master of Architecture

Carleton University

Ottawa, Ontario

(C) 2021, Freed Gomes 


\begin{abstract}
What if architecture became street art? This thesis explores alternate ways to see the city - and the invisible terrains that are hidden within cities - through the lens of "glitch" territories and fiction. These invisible cities are born from intuition and draw sustenance from theory - including the work of Roland Barthes and Italo Calvino. The thesis follows photogrammetry protocols used in heritage documentation - gathering, processing, consolidation of data, underlined with manipulation of techniques on photography, photogrammetry, and writing, respectively. Consequently, this thesis examines the role of authorial agency and subjectiveness of the reader, as it is used in Calvino`s literary production, by revisiting it with digital imagery. The fictional essays are told figuratively by the protagonist of of Calvino`s Invisible Cities `s - Marco Polo - where he reveals "Glitch-Visible Cities". There, he departs into a universe of sprayed canvas and pixels to unnest the hidden pluriverse virtues of Ottawa and its murals.
\end{abstract}

Keywords: Glitch, Invisible Cities, Street Art, Photogrammetry, Photography. 


\section{Acknowledgements}

As of today, we are considering going fo the $3^{\text {rd ld lockdown }}$ of the year. Within such dynamic circumstances, this research is certainly a result of emotions, motivation, engagement, disengagement, instability, but ultimately of a brain in storm. For all my family, friends and colleagues who helped me to overcome such challenging times, my deepest gratitude.

Thank God, who allowed me for a great reencounter in the last months. Thanks to my family that was able to be remotely there for me. Mom and grandma, the person who writes this essay today is the same one that you taught to dream.

I would like to express my great honor in being tutored by Dr. Stephen Fai. With very few words and kindness you change so much. Thanks Steve, for helping me dream. Lastly, I want to thank my thesis classmates Amanda Lapointe, Devon Mroar, Julie Ivanoff and Michele Duong. This research is embodied with our laughs and thoughts. Josh and Priscila, thanks for proving the values of friendship. I like to think that this would have been a different version without all of you. However, I like this version more. 


\section{Table of Contents}

Abstract............................................................................

Acknowledgements.............................................................iii

Table of Contents.....................................................................iv

Glossary..................................................................v

List of Illustrations................................................................vi

Introduction..................................................................... 1

Chapter 1: The Cultural Siginificance of Graffiti and Street Art....4

1.1 Social and spiritual values..................................................

1.2 The conservation dilemma......................................................

Chapter 2: Photography and Street Art.....................................11

2.1 Roland Barthes Studium and Punctum...................................11

2.2 Photography as mediator...........................................................11

Chapter 3: Calvino`s Invisible Cities.....................................17

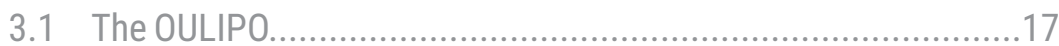

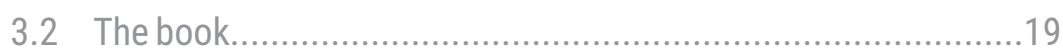

Chapter4:Research Proposal.............................................22

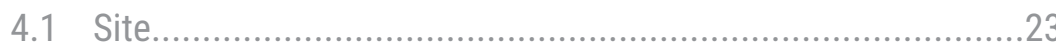

Chapter 5:Three-phase process...........................................25

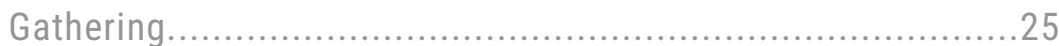

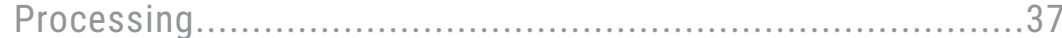

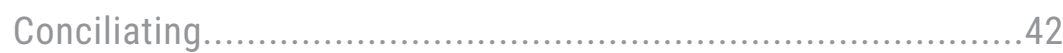

Chapter 6: Glitch-Visible Cities..........................................45

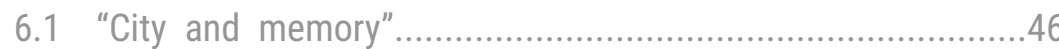

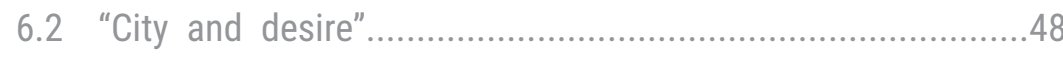

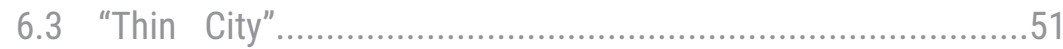

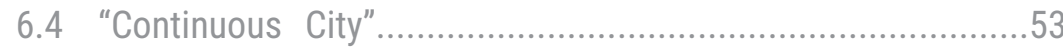

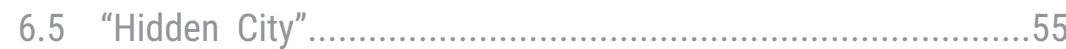

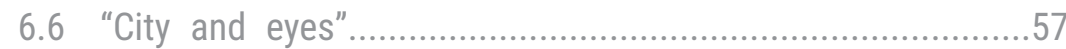

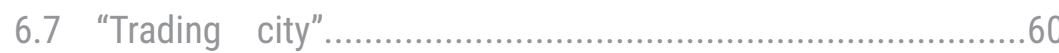

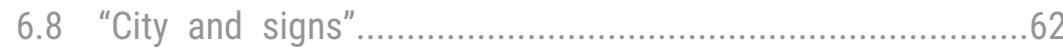

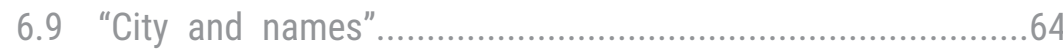

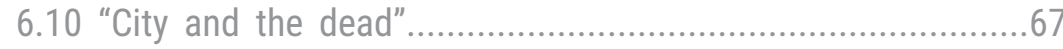

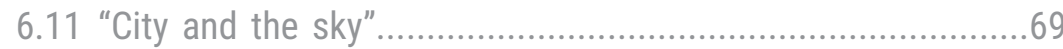

Conclusion................................................................71

Bibliography...................................................................74 
Glossary

Glitch - a digital mallfunction that might lead to aesthetic failure. 


\section{List of Illustrations}

Illustration 1 - JR, Los Surcos de la Ciudad, Maria Corbolan Ferandez on stairs, Cartagena, Spain, 2008, accessed on March 30, 2021 at https://www.jr-art.net/projects/carthagene-espag ne... ...3

Illustration 2 - Ben Birchall, Mobile Lovers by Banksy, accessed on March 30, 2021 at https://www.digitalspy.com/showbiz/a569550/ banksy-says-mobile-lovers-artwork-should-stay-at-bristol-boysclub/. . .8

Illustration 3 - Koen Wessing, Nicaragua, 1979, accessed on March 30, 2021 at http://www.dreamideamachine.com/en/ $? \mathrm{p}=42828$. . .12

Illustration 4 - BLU, MUTO a wall-painted animation, 2008, mosaic of screenshots, accessedon March 30, 2021 at https://www. youtube.com/watch?v=uuGaqLT-g04\&t=184s. .14

Illustration 5 - JR, 28 Millimètres, Face 2 Face, Separation Wall, Security fence, Palestinian side, Bethlehem, 2007, accessed on
March 30, 2021 at https://www.jr-art.net/projects/israel-palesti ne. 15

Illustration 6 - Stephen Fai, subway in Brussels, December 9, 2012, photograph, Brussels, acessed on October 4, 2020 .

Illustration 7 - Stephen Fai, subway in Brussels, December 9, 2012, photograph, Brussels, acessed on October 4,2020

Illustration 8 - Freed Gomes, Arpi's mural, Ottawa, March 2021, photograph. .26

Illustration 9 - Freed Gomes, Arpi's mural, Ottawa, March 2021, photograph. .27

Illustration $10 \quad-\quad$ Freed Gomes, Ryan
Smeeton`s mural, Ottawa, March 2021,

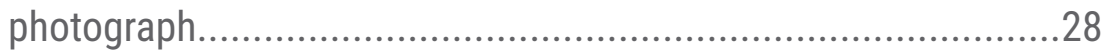

Illustration 11 - Freed Gomes, Otown`s mural, Ottawa, March 2021, photograph. ..29 
Illustration $12 \quad-\quad$ Freed Gomes, Armstrong St. and Garland St., Ottawa, March 2021, Illustration 18 - Freed Gomes, Giant, Ottawa, October 2021,

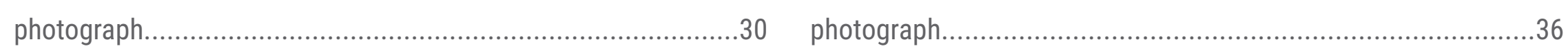

Illustration $13 \quad-\quad$ Freed Gomes, Sommerset Illustration 19 - Structured motion around the object..............37 Square Park, Ottawa, March 2021,

photograph......

..31 Illustration 20 - Absence of structured motion around the object....37

Illustration $14 \quad$ - $\quad$ Freed Gomes, Sommerset Illustration 21 - Leading photograph overlaid with secondary

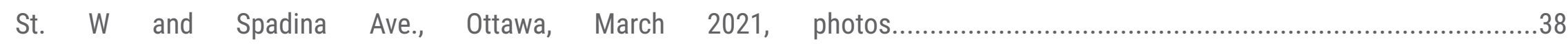

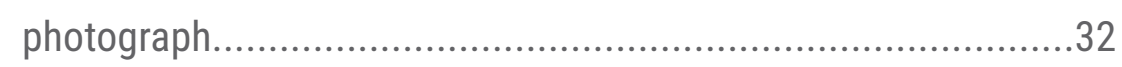

Illustration 22 - Masking of blurred area...................................38

Illustration $15 \quad-\quad$ Freed Gomes, Armstrong St.
and Hamilton Ave. N, Ottawa, March 2021,

Illustration 23 - Glitch mesh. . .40

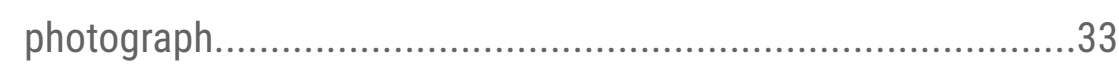

Illustration 24 - Pixels as continuous to each other. .41

\begin{tabular}{|c|c|c|c|c|}
\hline Illustration & 16 & Freed & Gomes, & “Curiosity \\
\hline killed the & cat!" & Ottawa, & March & 2021, \\
\hline
\end{tabular}

Illustration 17-FreedGomes, “Looktotheleft!” Ottawa, October2021, photograph. .35 



\section{Introduction}

The portrayal of street art in a book or a photograph and the often-frontal viewing of a mural in the streetscape are, somehow, generic frames from which everybody can share. As a reminiscence from graffiti, whose nature resides in abstraction, the street art can hide messages powerful enough to resignify the murals themselves or even the surrounding territory. The greatest distinction between graffiti and street art is the targeted audience. The former communicates within the graffiti community through encrypted signs that appear as abstractions to the uninitiated. The latter often uses figurative language to speak to the community at large (the city). The coded messages of graffiti are indicative of social tensions inherent to urban life. As Barthel has proposed "For those who create it, graffiti is not simply a paint on a wall. Rather it becomes a way of thinking about and occupying a comfortable space within the dominant culture."1 This reasoning, embodied in the nature of graffiti, I argue, is shared with street art. Murals animate the inert body of a painted wall and reveal the transformative power

1 Barthel, "Perceptions of Graffiti in Ottawa: an Ethnographic Study of an Urban Landscape., 46 of images. This thesis seeks to broaden the visual vocabulary of murals and the streetscape as it relates to unveiling invisible urban phenomena through computational experimentation. It stems from an investigation at the intersection of street art and architecture as seen through the eyes of a photographer and photogrammetrist.

"Multi-image photogrammetry or Structure from Motion is a relatively new technique for accurate digital capture of 3dimensional objects and surfaces. The technique is practical and versatile and is increasingly being adopted for cultural heritage." 2 Conventionally, it is used to transform physical objects into digital facsimiles using two dimensional images processed by computer software. In order for the software to function properly, the photographer moves around or across the object or surface being recorded - assuring that there is a minimum of 60 per cent overlap of the images. In this thesis, I have proposed an alternative to this accepted method. My goal is not to capture the "reality" of the city, but rather to reveal the invisible cities that co-inhabit that reality. This alternative method peels away any residue of scale. Rather than consolidating the images into some simulacrum of this world,

2 McCarthy, "Multi-Image Photogrammetry as a Practical Tool for Cultural Heritage Survey and Community Engagement”, 176 
it causes the images to explode into a previously unknown terrain. This new terrain has the capacity to trigger a diversity of thoughts - waking dreams - akin to what Spiller has called the "tumult of objects, vectors and humanity"3 found in Surrealism.

The navigation of these new terrains takes inspiration from Calvino's Invisible Cities (1972) to post-rationalize the spaces and objects and to animate them with new narratives. As the narratives speak to the terrain, invisible cities are unveiled through simultaneity, multivalency, and nesting qualities that address the underlying question in this research: What if architecture became street art? Inherently ephemeral, street art represents a genuine cultural force that is potentially transformative to cities. Subject to erasure, street art is a cultural expression that embodies temporality like no other. Moreover, technology-aided responses in architecture have helped to peel this temporal character away from the traditional Cartesian formulation. By fusing street art with architecture, the newly revealed terrains - the Glitch-Visible cities - in this thesis become equally more "rhythmic, fleeting and unpredictable" 4 (temporal) as contrasted with "architecture's traditional concern 3 Spiller, Architecture and Surrealism: A Blistering Romance, 127 $4 \quad$ Judson, "Beyond Space? : Exploring the Temporality of Architecture ., 1 with permanence, stability, and space" ${ }^{5}$ (spatial). This allows us to see new possibilities that were, until now, hidden.
$5 \quad$ Judson, "Beyond Space? : Exploring the Temporality of 


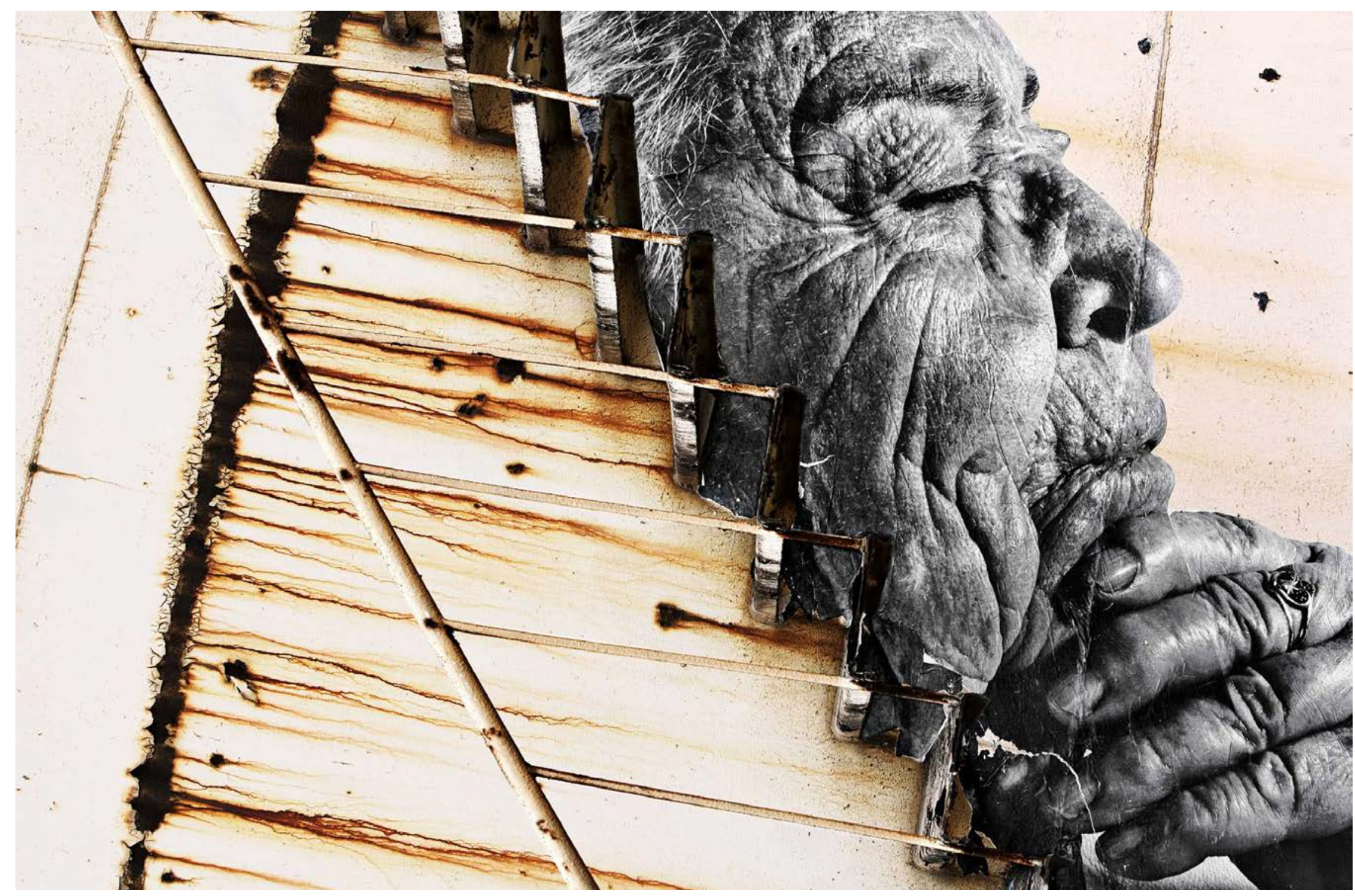

Fig. 01 - Los Surcos de la Ciudad, Maria Corbolan Ferandez on stairs, Cartagena, Spain, 2008, at https://www.jr-art.net/projects/carthageneespagne 


\section{Chapter 1: The Cultural Siginificance of Graffiti and Street Art.}

This chapter primarily discusses the social and spiritual values, whose innovative addition by the Burra Charter allowed for the acknowledgement of the cultural significance of graffiti and street art. On a second moment, the overview on these values will enable the articulation of the minor superficial and subcutaneous strata that embody these phenomena in the cities. Everything that the city comprises is manifested through a singular human agent, which is related to the whole. This wholeness is comprised of parts and therefore those parts are intrinsic in a complex interwoven set of relations. For instance, graffiti and street art offer as much in the immediate individual realm (the writer, the painter, the mural) as in the collective realm (the network of writers, painters, and murals). Cultural phenomena are deeply embedded in this definition of wholeness, likewise for graffiti and street art. Therefore, acknowledging culture within such expressions means acknowledging that they actively engage with the city at large. Thus, two important definitions under conservation frameworks need to be emphasized in this chapter: cultural significance and values. As stated in the Burra Charter, cultural significance is any "aesthetic, historic, scientific, social, or spiritual value for past, present, or future generations" ${ }^{\prime}$. Meanwhile, values are embodied "in the place itself, its fabric, setting, use, associations, meanings, records, related places, and related objects"7. In other words, cultural significance is a visualization at large comprised of the minor forces that operate within values. The juxtaposition of these definitions with activities of such subversive nature offers a clear visualization of the current nature of graffiti and street art while unfolding the challenges at stake.

\subsection{Social and spiritual values}

The charters issued by ICOMOS recommend guidelines to all the specialists involved in the conservation and restoration of heritage assets. More recently, with the addition of social and spiritual values in the Burra Charter, more recommendations arose focused on things of intangible nature. "The important innovation in the Burra Charter is social or spiritual value, formerly defined

6 Australia ICOMOS Burra Charter, 2013, Article 1, 1.2 
in the Charter's explanatory notes as 'the qualities for which a place has become a focus of spiritual, political, national, or other cultural sentiment to a majority or minority group'." 8 These changes are a direct response to previous heritage frameworks as they have been "continually subject to entropic processes despite the efforts of heritage institutions." ${ }^{\prime 9}$ Similarly, both society and its institutions while deeply rooted in a capitalist system, lean towards an understanding of reality that favors things of exact, tangible, and quantitative natures to the detriment of abstract ones. This means that evaluating, assessing, or recommending something is consequently measuring, counting, and ultimately touching it, so the tangible nature facilitates the visualization in both cartesian and capital systems. Conversely, anything outside of such definitions that requires assessment will very often demand more complex responses. What spiritual and social values unfold, then, is a primary expansion from a technical and theoretical basis (scientific, historic, and aesthetic values), assessed by specialists only, towards one more intuitive and participatory. Alois Riegl, when categorizing values, separates them as:

\footnotetext{
$8 \quad$ Kalman, Heritage Planning: Principles and Process, 201

9 Merrill, "Buffing and Buffering Blu: The Societal Performance of Street Art, Heritage Erasure and Digital Preservation in Berlin”, 2
}

'"present-day' values, which are more societal and change considerably over time, and which are distinguished from 'memorial' values, which are mostly technical and remain relatively constant. The latter are best identified by professional specialists, such as historians, architectural historians, and archaeologists; the former is better expressed by interested, non-professional members of the community." 10

Consequently, "An appreciation of the meanings of the place may be even more elusive: acquiring this certainly requires the insights and awareness of lay people, reinforcing the need for community engagement."11 These arguments are crucial to acknowledge cultural significance within graffiti and street art, since they are expressions shared by multiple stakeholders. This scenario allows them to merit preservation and recognition within formal and legal institutions.

Another important recommendation results from social and spiritual values in the Burra Charter is that "Cultural significance may change over time and with use." ${ }^{12}$ Therefore, a specific value 10 Kalman, Heritage Planning: Principles and Process, 202

11 Kalman, Heritage Planning: Principles and Process, 203

12 Australia ICOMOS Burra Charter, 2013, Article 1, 1.2 
might carry a temporal attribute within it. By introducing such recommendations, the heritage frameworks allow us to look at cities as fleeting organisms. The Article 1.2 in the Burra Charter also adds that: "Places may have a range of values for different individuals or groups,"13 to which Kalman responded:

"Values are relative, not absolute. Because of the social origins of values, it follows that different parties may hold different sets of values with respect to a historic place or may assign different weight to the same values. In this respect, values often conflict with one other."14

This unfolds an unprecedented case for the relative and changing nature of things versus an absolute and permanent one. In fact, this is a moral testimony over the ephemeral nature of cities, more than anything else. For instance, if the city is comprised of this temporal phenomenon known as street art, and it is fleeting, then there are aspects of the city where the city is fleeting because it is embodied by things like street art. However, the adoption of time represents, ultimately, a challenge in the sense that if we believe that cities are ephemeral our economy collapses. Nonetheless, it is by relying on

13 Australia ICOMOS Burra Charter, 2013, Article 1, 1.2

14 Kalman, Heritage Planning: Principles and Process, 203 permanent and fixed qualities that economical value grows. This highlights the complex innovative character of social and spiritual values in a deeply rooted capitalist society. In this scenario, graffiti and street art emerges as the embodied tension of all these variants of time and multiple stakeholders, forcing both heritage institutions and communities into alternative ways of looking at cities.

To understand how values emanate from graffiti and street art, we might as well look at the city as urban territory: "For those who create it, graffiti is not simply a painting on a wall. Rather it becomes a way of thinking about and occupying a comfortable space within the dominant culture." ${ }^{15}$ Street artists, meanwhile, generally place greater value on traditional conceptions of aesthetic merit and creative development in their attempt to establish fame or recognition. Therefore, street artists tag the community while graffiti is intended in communicating within its cohorts only. They also share reminiscences of illegality and territorial discourse from graffiti. Thus, this research borrows the term "outsiders"16 (writers, street artists) and "insiders" (community), coined by Samuel Merrill,

15 Barthel, "Perceptions of Graffiti in Ottawa: an Ethnographic Study of an Urban Landscape., 46

16 Merrill, Keeping it Real? Subcultural graffiti, street art, heritage and authenticity, 382 
to illustrate the articulation of such forces within the city. As such, graffiti is often seen by the community as an act of vandalism and depredation of the public built assets. Therefore, tags, throwies or pieces have values attributed differently to whether it is seen from an "outsider" or an "insider". In street art, however, the community often sees it as something positive, leading to greater tolerance over murals. However, on what concerns conservation, "outsiders" and "insiders" are most likely to stand on opposite sides. The "outsiders" acknowledge the impermanent nature of graffiti and street art. Consequently, the act of conserving a mural will hardly ever come from "outsiders" but rather from the community.

\subsection{The conservation dilemma}

When analyzing graffiti, Merrill highlights the "political, chronological, spatial, social and cultural subcategories that are the result of a range of different motivations."17 His reasoning adds the superficial social strata of the open public space to the entropic one of the murals. The addressing of the word "superficial" is to suggest the surface of the open streetscape as superficial to the

17 Merrill, Keeping it Real? Subcultural graffiti, street art, heritage and authenticity, 370 underground domain. Graffiti is a movement that has its origins rooted in the subway stations. From a tangible perspective, a mural is comprised of many layers: the structure, the wall, the screen, the sprayed painting, sometimes even the layers of chemical erasure, until finally a writer or a street artist reboots the whole cycle by painting something new on top of it. Meanwhile, from an intangible angle, these urban expressions carry many layers of political and social character within them. This is mostly due to how frequent their occurrence in the city is, whose ultimate behavior reflects their response to surrounding urban space. Therefore, when analyzing graffiti and street art, one is necessarily investigating the spontaneous facets of the city. As such, since most spontaneous reactions lead to the exposure of vulnerabilities, it is not a surprise how much graffiti and street art reveal not only the potentials but also the weaknesses of the urban realm. Yet, as a phenomenon inherent to most urban centers around the globe and despite some distinguishing qualities with respect to local and national settings, graffiti and street art collectively add to interests of its globalized nature with common aesthetics and practices. This allows us to affirm that by tracking down the occurrence of such complex 
movements, we inevitably analyze the world at large.

For instance, in 2015, the world celebrated street artist Banksy unleashed an unprecedent case for the safeguarding of street art in Bristol, England. His authorial piece "Mobile Lovers" was involved in a controversial legal process that illustrates the tension of forces pressing on street art, community, and legal institutions. Briefly, the narrative started with a painted plywood door of a Youth Club facing the street. Soon, the piece was placed inside the building, while inviting the public to visit the work in exchange for small donations. The piece stayed in-situ until after accusations of theft, the city reclaimed it to be transferred to the Museum of Bristol until further assertion on the ownership of the piece was made. Amid challenges on heritage guidelines and public consultation, the dispute was finally couched in terms of elucidating the artist's intentions. An unusual precedent, somehow, since it discusses the authorial intentions of the piece rather than the most common questioning of the authorial character itself. For instance, all parties agreed upon the thread of "Mobile Lovers" as a "gift" from Banksy, which

"reflects an increasingly established socio-moral urban

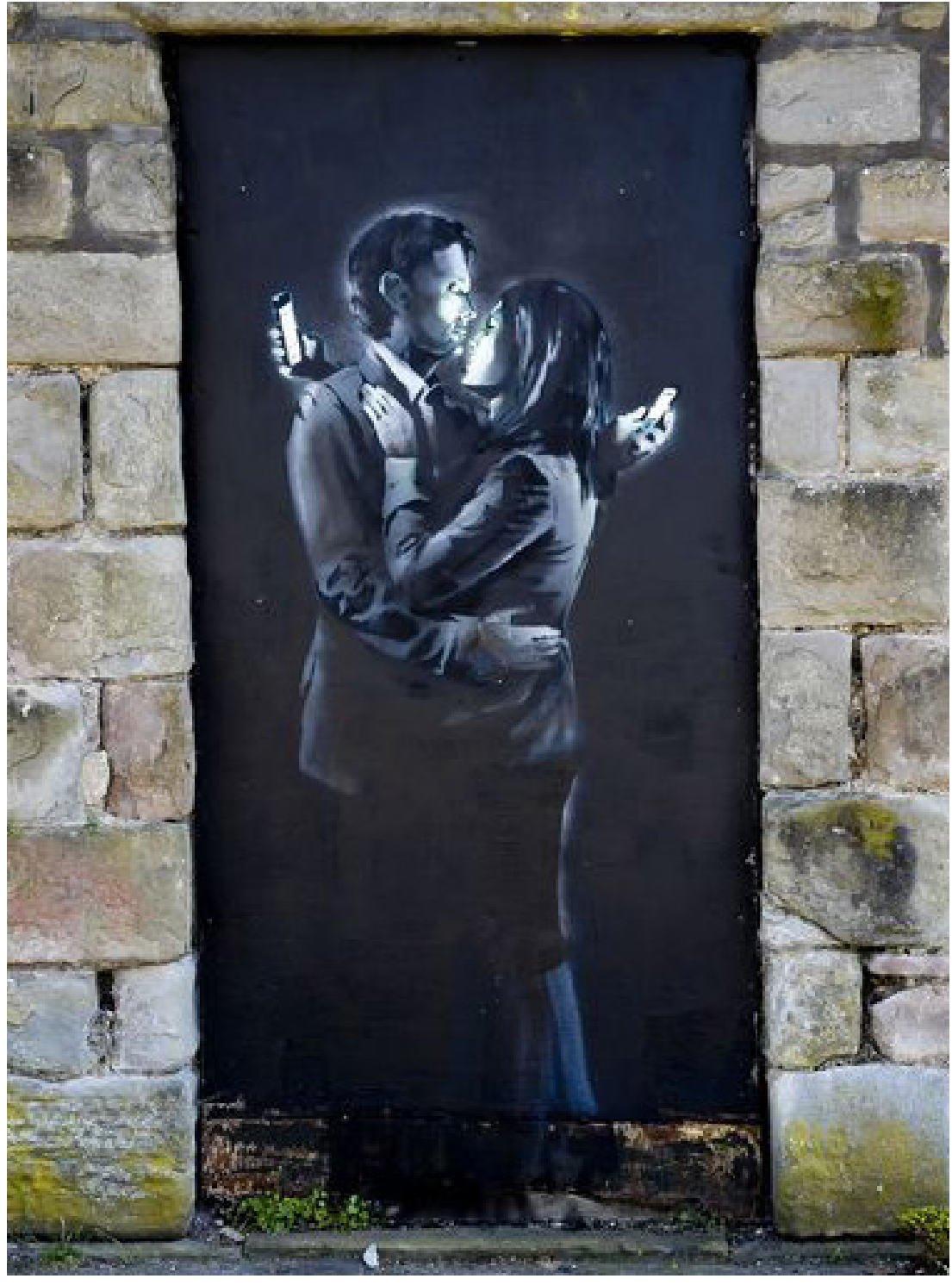

Fig. 02 - Mobile Lovers, Banksy, at https://www.digitalspy.com/showbiz/ a569550/banksy-says-mobile-lovers-artwork-should-stay-at-bristol-boysclub/ 
norm regarding the value of street art to communities, which in turn sets parameters for the actions perceived as being appropriate responses to its creation/discovery, although it should be noted that this is a historically recent understanding that is still contested." ${ }^{18}$

The story closes with Banksy being publicly asked to write a letter addressing the original intent of possession of "Mobile Lovers", to which he replied stating Mr. Stinchcombe, owner of the club, as the intended beneficiary. "The tension at the basis of this lawful yet morally problematic practice is grounded in the legal recognition of the rights of property owners to the tangible works on their walls over the moral rights of street artists to control the first distribution of their work, and the rights of communities to assert ownership over works that they regard as public art intended for their enjoyment,"19 forcing legal institutions and the community into alternative means of interpretation.

While reflecting upon the temporal values of graffiti and street art, another significant feature is unfolded: photography.

\footnotetext{
18 Hansen, Banksy's subversive gift, 288
}

19 Hansen, Banksy`s subversive gift, 285
The posed resistance against conservation is in the most inner nature of these expressions. "The perpetual impermanence of the image (or the forced and enforced fluidity of city surfaces) is amongst the most important traditions"20 of graffiti and street art. Both, then, understand the impermanent nature of the "skin" of the city as very few expressions do. To better illustrate this imagery, this paragraph draws an analogy between these phenomena as parasites and the city surface as skin. Graffitis momentum, evidenced through "visual control over subway trains during the 1970s" in New York, explodes subcutaneously to the larger body of the city. Writers learn from the motion of public transportations, whose silent work is an invisible epidemy to the "epidermis" of the streets. When Graffiti emerges on the open public space, it coexists with the visual matrix of weathering, decay, abandonment, erasure, and exposure. It establishes upon processes that are inherent to the cycle of a modern city. Street Art, as a later bifurcation of this movement, is equally invested in perpetuating the ephemeral discourse from graffiti. The idea of conserving, which presumes the permanence of things, goes then reversely to the impermanent nature of these expressions. However, this divergence of interests

20 Waclaveck, Graffiti and Street Art, 12 
unfolds one significant attribute in their culture: photography. Since they rely upon the constant erasure and replacement of their production, to exist as territorial rhetoric, photography becomes the medium simultaneously capable of documenting and assuring the ephemerality of the production. Thus, photography draws an eloquent paradox by immortalizing an intangible visual memory while assuring the ephemerality of the tangent elements of a mural. Hence, photography became a broadly approved and diffused mean between street artists and writers. 


\section{Chapter 2: Photography and Street Art}

Photography is used consistently in the scope of this research. As such, this chapter stems from an analysis of the concept of studium and punctum introduced by Roland Barthes in Camera lucida. The book introduces early technical vocabulary on photography, followed by Barthes' great tone of subjectivity. The notes on studium and punctum in this chapter, though, are rather introductory, as its application to the research is illustrated in chapter Two. Additionally, an analysis on the mediation of photography within street art is illustrated with the works of BLU and JR, whose works make a claim for alternative ways of production.

\subsection{Studium and Punctum}

Barthes introduces studium and punctum by speaking of "adventure" in a photograph. He states: "I understood at once that its existence (its "adventure"),"21 - by adventure he means the unusual but often surprising quality of a photograph - derives from "the co-presence of two discontinuous elements, heterogeneous in that they did not belong to the same world (no need to proceed to

21 Barthes, Camera lucida: reflections on photography, 23 the point of contrast): the soldiers and the nuns." ${ }^{22}$ By detaching the soldiers from the nuns - Fig. 03 - Barthes can identify studium, a word derived from Latin referred to "study" 23 ; and punctum, also from Latin, meaning a "a small, distinct point." ${ }^{24}$ Accordingly, he defines studium as the basic cultural elements that embody a photograph, which in this case are the soldiers, the war, the disorder, the degradation, the chaos, etc. These elements assure that by studying the photograph, the spectator can presume its context. Punctum, on the other hand, he identifies as the nuns. Accordingly, Barthes defines it as a heterogeneous element to those from studium, an incongruence that punctuates the "adventure" in the photograph showing that something is not quite right. Overall, the punctum helps to broaden the rhetoric of the photographer, as a storyteller, since it results from the subjectivity of his eyeball positioning.

\subsection{Photography as mediator}

Photography can also mediate the production of murals on the streets. The Italian street artist BLU combines his street 22 Barthes, Camera lucida: reflections on photography, 23

23 Morwood, Pocket Oxford Latin Dictionary: Latin-English 24 Morwood, Pocket Oxford Latin Dictionary: Latin-English 


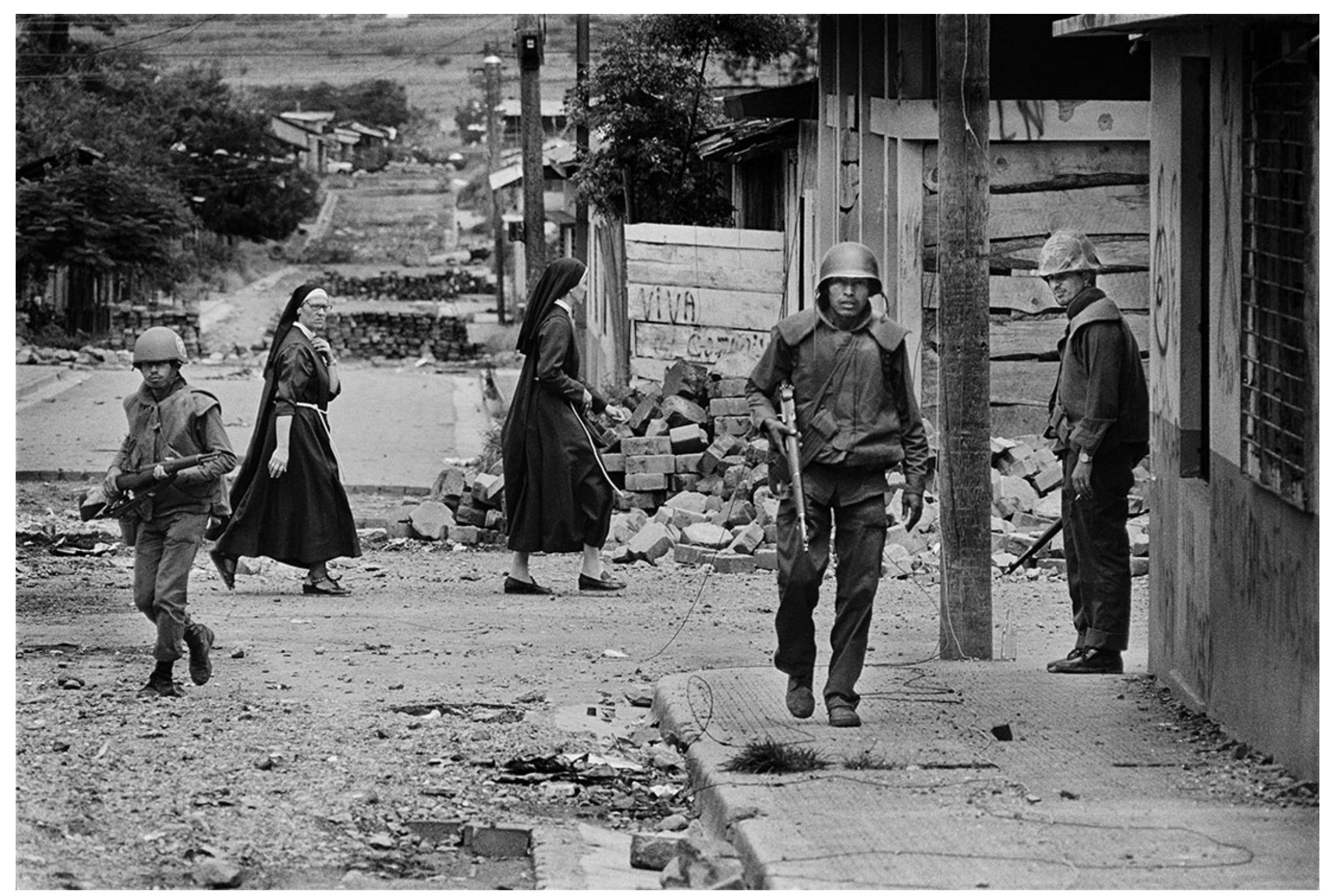

Fig. 03 - Koen Wessing: War in Nicaragua, 1979 
illustrations with stop motion animation. As a result, his visual vocabulary has often enormous and panoramic murals. Through repetitive erasure and over-layering, BLU narrates stories where characters come to life as the frames navigate around the city. As he very often chooses places of abandonment - often forgotten or ignored by the rush of daily life - his productions also argue for loss and erasure. Nonetheless,

"The story of these murals and their plot encompasses processes of ruination and renewal, gentrification and neighborhood change, and acts of iconoclasm and iconoclasm, making them a useful case through which to explore street art's ability to index the complexities of heritage's relationship with erasure and the manner by which this relationship can be refracted through digital media,"25 attesting once again the singular character of street art in forcing divergent forces to negotiate. For instance, in his 2008 animation MUTO, BLU develops an eloquent work that "foregrounds urban wandering as inscription and vice versa." ${ }^{26}$ The plot mirrors the cycles of the modern city: consumption, reproduction, decay, and $25 \quad$ Merrill, Buffing and Buffering Blu: The Societal Performance of Street Art, Heritage Erasure and Digital Preservation in Berlin, 4

26 Chang, Animating the City: Street Art, Blu and the Poetics of Visual Encounter, 217 temporal circularity while claiming for play and potential. A visual imagery contained in a white liquid stain whose clarity in bold black lines delineates the silhouette of assorted characters. As it spreads over the walls, sidewalks, and every other potential street element, the white liquid pushes his visual imagery to the foreground while juxtaposing, and at times even borrowing from the tags and murals in the background. In a fast-paced sequence of frames, BLU reclaims for play and potentials with ruins, abandoned terrains, shade, and ultimately the city. His work fills in the often-invisible canvas that is the public space.

Alternatively, the practice of the French artist's JR has been mostly characterized by oversized photographic posters depicting intimacy in a symbiotic process amid social documentary photography and street art. His first portrait depicted the rioting immigrant youngsters of the Parisian suburbs at Clichy-Montfermeil, "28 Millimeters", 2004. His work soon spanned across the Middle East with "Face 2 Face", 2007, articulating with Israelis and Palestinians on both sides of the West Bank Barrier. In "Women are Heroes", 2008-2010, JR evoked the empowerment of female victims of rape, war, or other side-effects of political extremism in the slums of Kenya, India, Rio de Janeiro, and Cambodia. He continued gaining 

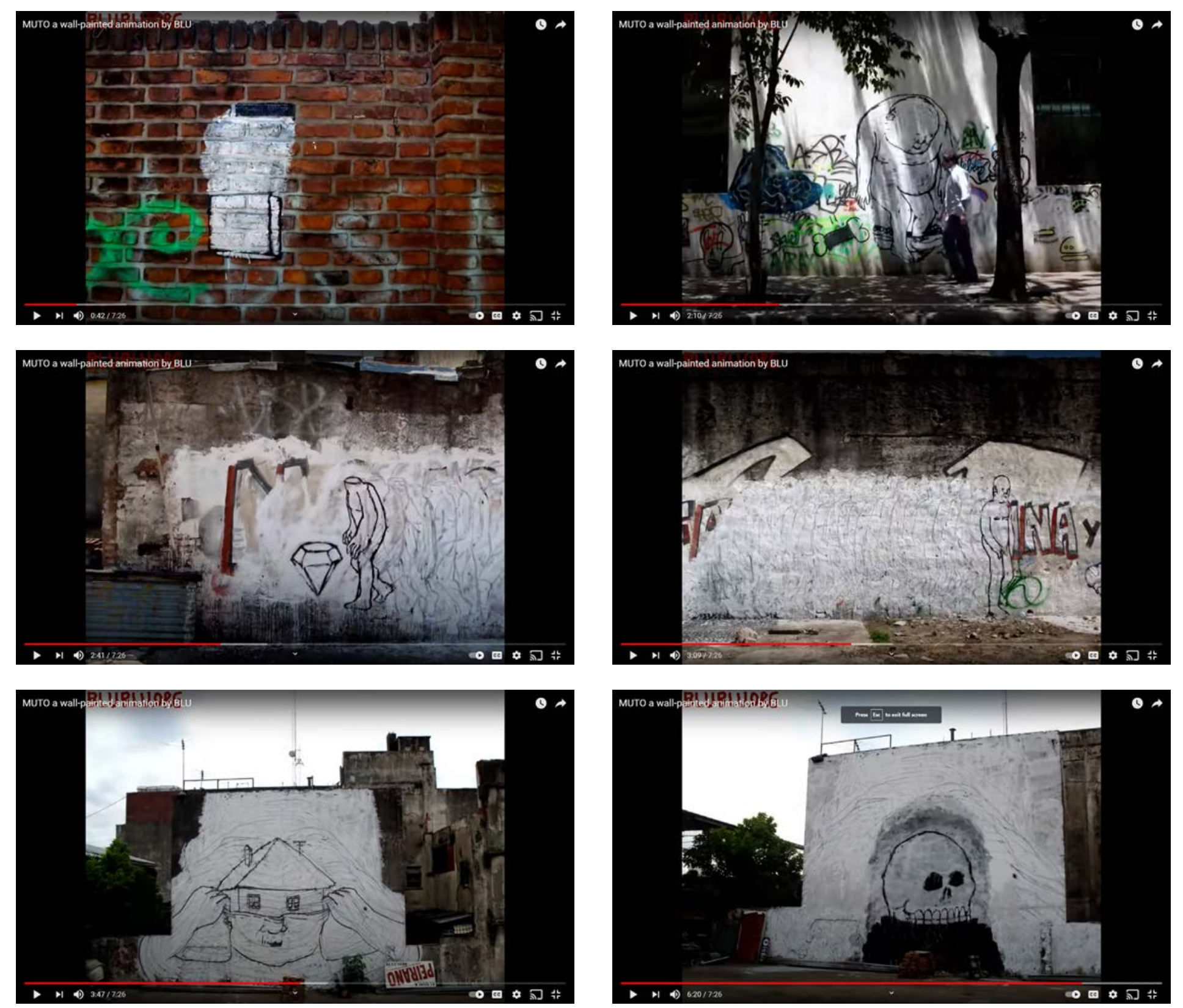

Fig. 04 - MUT0 a wall-

painted animation by BLU, 2008, mosaic of screenshotsextracted from YouTube. 


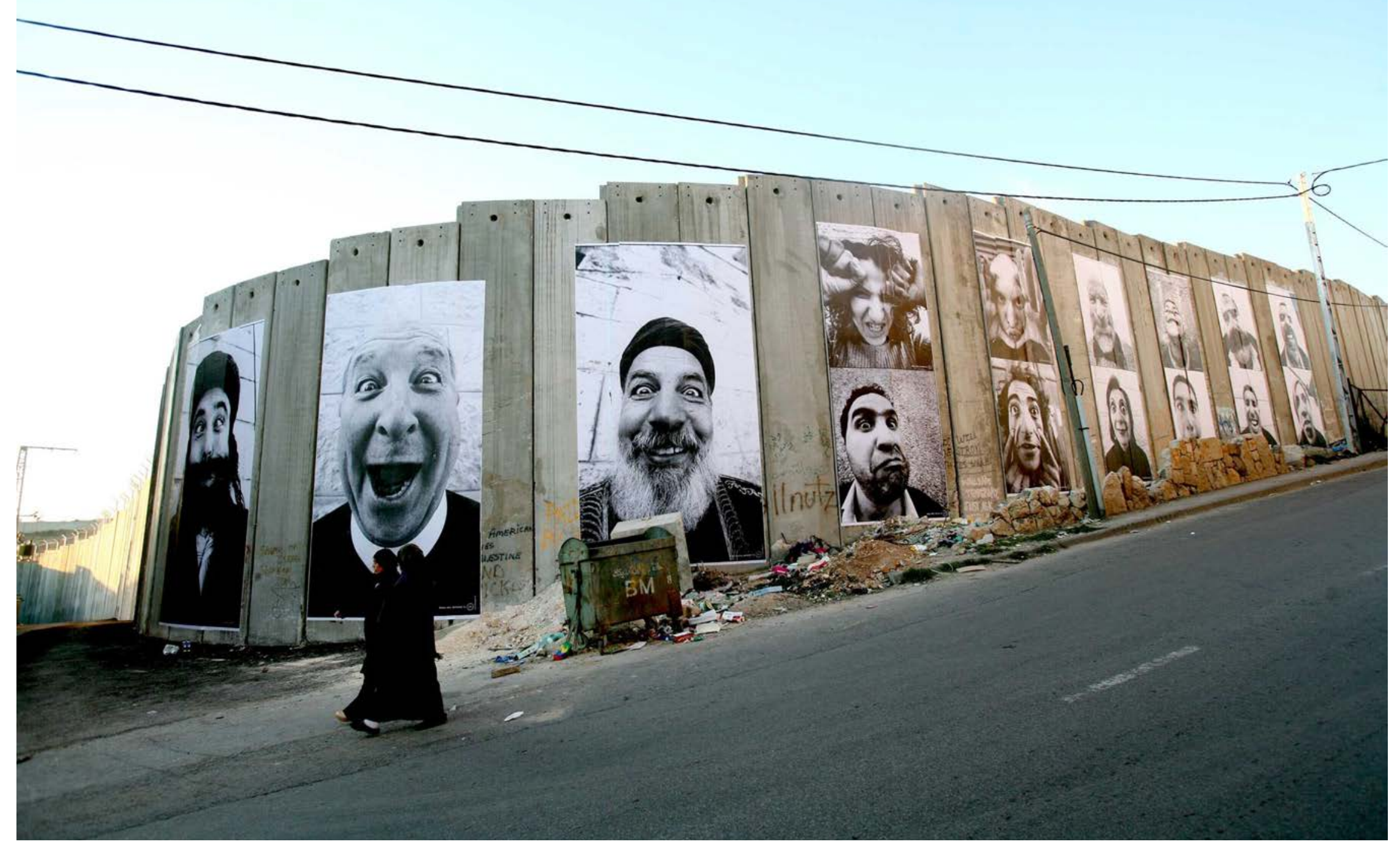

Fig. 05 - 28 Millimètres, Face 2 Face, Seperation Wall, Security fence, Palestinian side, Bethlehem, 2007 
new territories in the poor areas of Berlin, Cartagena, La Havana, Los Angeles, and Shanghai by staging the ageing of the population with "The Wrinkles of the City", 2008-2013. These early projects were made without permission, a strategy that allowed him to "infiltrate" places with relevant social and aesthetic impact. Among all works, the common thread has been the subversion to "the established rules of spectatorial desire in that they aesthetically evoke the empowerment of the dispossessed subject." ${ }^{27}$ Additionally, JR unleashed a new take on the apparatus of propaganda in the context of modern cities. When criticizing publicity staging, Anna Waclawek, an art history Professor at Concordia University affirms: "Advertising is always trying to place itself a million miles above us, looming down with the shiniest, flashiest most disconnected depictions of beauty, just out of reach like the rest of its promises, and I find myself trying to get down below that, at eye level, where people are walking, and to depict the life that exists here at the bottom edge, our ordinary reality as it remains connected to the ground." ${ }^{28}$

While "advertising" the people who are directly involved in the urban

27 Petra. "Urban Figures, Common Ground: JR and the Cultural Practices of Perception.", 05

28 Wacławek, Graffiti and Street Art, 86 conflicts around the globe, JR marked another transition in the history of social documentary photography and street art. His work patches a challenging social fabric with his art. 


\section{Chapter 3: Calvino`s Invisible Cities}

This chapter analyzes Invisible Cities by Italo Calvino, published in 1972. It also investigates the variants external to the literary work and how they drew great influence from it. The book is a surrealist novel where subjectiveness charges the authorial tone. Thus, to analyze Invisible Cities necessarily means to question Calvino`s anguishes and contentment. Nonetheless, the dizziness in the constantly modified urban and anthropological territories around Calvino triggered social and temporal disparities to unfold new lifestyles and visual forms. The Italian writer was living in France by the time he wrote and published Invisible Cities. Paris was dramatically influential to Calvino`s work. A city whose eyes watched the magnificent funeral rites offered to the muse of rationale and order in architecture, Le Corbusier, in August 1965. In a paradoxical gesture the capital also watched the rise of ambitious architectural design and theory, epitomized by the orderly disordered Pompidou National Center for Art and Culture by Renzo Piano and Richard Rogers in 1969. Yet,

"Paris was also, it must not be forgotten, the home of anthropologist Claude Lévi-Strauss whose observations on Brazilian, Caribbean, and Indian cities in "Tristes Tropiques" (A World on the Wane [1955]) privileged the city as the very definition of humanity ("la ville..., la chose humaine par excellence"), as architect Aldo Rossi recalled during that period." 29

Accordingly, a city that celebrated the human agency, inspiring the subjective reasoning of Surrealism. Paris, thus, was an external force to Invisible Cities nurturing its autobiographical character.

\subsection{The OULIPO}

Calvino was a member of a French literary group named OULIPO - OUvroir de LIttérature POtentielle. He absorbed many influences from the members, whose work relied on the investigation of mathematics and science to promote literature as a combinatorial machine. Calvino`s faith on the permutation of words underlined his work in Invisible Cities. Moreover, it offered the core reasoning behind Cybernetics and Ghosts, a remarkable lecture delivered in Turin in 1967. The pursuit in introducing mathematics

29 Modena, Italo Calvino's Architecture of Lightness: The Utopian Imagination in An Age of Urban Crisis, 8 
to literature followed a world struck by the revolution within the discrete mathematics of computer programming. For instance, when arguing on the exhaustiveness of the combinatorial play in Cybernetics and Ghosts, Calvino said:

"I am not now thinking of a machine capable merely of 'assembly-line' literary production, which would already be mechanical in itself. I am thinking of a writing machine that would bring to the page all those things that we are accustomed to consider as the most jealously guarded attributes of our psychological life, of our daily experience, our unpredictable changes of mood and inner elations, despairs and moments of illumination. What are these if not so many linguistic 'fields', for which we might well succeed in establishing the vocabulary, grammar, syntax, and properties of permutation?"30

Ramón Llull, described as 'one of the fathers of the "Oulipian", is claimed as the author of the most influential system on Calvino`s thought. Dennis Duncan, on The OULIPO and Modern Thought, affirms:

“Calvino's literature machine, as we will see, explicitly places

30 Calvino, The uses of literature: essays, 12 an interpretative responsibility on the reader. Nevertheless, whether used for religious or poetic ends, Llull's Art demonstrates a theological confidence that inspiration is the result of a rigidly observed calculus, and not of a Romantic individualism. As such it presents Calvino with an ideal apparatus with which to drive the author-subject out of the creative process." ${ }^{31}$

Llull's branch of combinatorial system is illustrated by a series of diagrams, tables, and volvelles, that resembles an astrological chart.

"The diagram, in other words, is intended to elucidate the nature of God by taking His nine irrefutable 'Dignities' and showing that each may be read as a quality of another: His greatness is eternal, etc." ${ }^{32}$ On a minor scale, Invisible Cities's narratives collide qualities within themselves to unravel cities of unpredictable nature. On a broader scale, though, it represents a literary work that announces the massive migration of the world at large towards computerized environments. Nowadays, as the world still watches branches of our daily existence being displaced into cybernetic environments, the Oulipians branch of literature is still capable of offering parameters

31 Duncan, The OULIPO and Modern Thought, 107

32 Duncan, The OULIPO and Modern Thought, 102 
for issues of contemporary nature.

The OULIPO and Roland Barthes are contemporary to the rise of computers, and despite rarely crossing each other, they trace their roots to the cybernetic moment of the early 1950s. Calvino explicitly expressed his admiration for Barthes in a letter addressed to Grazia Marchianò on 21 December 1965, when he wrote "[Barthes] is perhaps the contemporary critic I admire the most. He is not only a highly intelligent critic but a fine writer." Structuralists and Oulipians were drawing great remarks on the figure of the author. For instance,

"At exactly the point that Strachey was programming the Manchester University Computer to compose love letters, across the Channel, the French cyberneticist Albert Ducrocq was building a robot which would also be capable of producing linguistic output. Christened Calliope after the Greek muse of epic poetry, Ducrocq's machine was, as he put it, a poète électronique (...) Calliope's electronic poems raise the possibility of the text voided of intention, free of authorial subjectivity, an idea which will find its theoretical apotheosis fifteen years later in Barthes's famous 'Death of the Author' essay." ${ }^{33}$

Calvino departed from this discussion to unfold a remarkable argument on the role of the reader, when he argued that "it is in the reading process that the machine-authored texts become charged with emotional value-a distinctly Barthesian manoeuvre." ${ }^{34}$ This reflection on subjective interpretation is the core argument in Cybernetics and Ghosts. Discussing the reader's mind also leads Calvino to emphasize, indirectly, the Surrealism as "the art movement that reckoned with impossibility, celebrated the juxtaposition of distinct realities, dissolved boundaries between inner and outer worlds, and championed imagination over realism." ${ }^{35}$

\subsection{The book}

This paragraph describes the structure of Invisible Cities by adding a tone of subjectivity to its analysis. In sum, the book represents a continuous effort in colliding objects and phenomena of distinct natures through 55 fanciful territories portrayed by traveler Marco Polo in letters exchanged with the emperor Kublai

\footnotetext{
33 Duncan, The OULIPO and Modern Thought, 30

34 Duncan, The OULIPO and Modern Thought, 110

35 Jessica Reed, "The Essence of Seeing: Surrealism, Relativity, and Quantum Mechanics," Nightingale, March, 2020
} 
Khan. Under 11 distinct rubrics, their conversations converge the realities and the potentialities of the city as the great exponent of the human agency: "Cities and memory," "Cities and desire," "Cities and signs," "Thin cities," "Trading cities," "Cities and eyes," "Cities and names," "Cities and the dead," "Cities and the sky," "Continuous cities," and "Hidden cities." The opening act, whose background is the city of Diomira, portrays the grandiosity in a land that resembles a mythological scenery. Meanwhile, it warns conservative readers through phallic architecture and a subtle sexual tone that Marco Polo is not afraid of disclaiming with honesty what unfolds behind his eyes:

"Leaving there and proceeding for three days toward the east, you reach Diomira, a city with sixty silver domes, bronze statues of all the gods, streets paved with lead, a crystal theater, a golden cock that crows each morning on a tower. All these beauties will already be familiar to the visitor, who has seen them also in other cities. But the special quality of this city for the man who arrives there on a September evening, when the days are growing shorter and the multicolored lamps are lighted all at once at the doors of the food stalls and from a terrace a woman's voice cries ooh!, is that he feels envy toward those who now believe they have once before lived an evening identical to this and who think they were happy, that time."36

Departing from mythology allows him to explore its literary artifices. I argue that the myth is the questioning of the absoluteness of reality. It unfolds underworlds, paradises, holy landscapes, but it also challenges the ordinary virtues of humans through empowered deities. Thus, Calvino is concerned in situating the reader in a comfort zone of wondering since mythology is situated beyond the grounded preoccupations of ordinary life. In a few pages, we see ourselves questioning, intrigued, and reclaiming our own reality as Marco Polo depicts cities from inanimate objects so familiar and trivial to our daily existence. In Armilla, for instance, Calvino reclaims the stiffness of metal pipes in the fragility of a territory in ruins.

"Abandoned before or after it was inhabited, Armilla cannot be called deserted. At any hour, raising your eyes among the pipes, you are likely to glimpse a young woman, or many young women, slender, not tall of stature, luxuriating

36 Calvino, Invisible Cities, 7 
in the bathtubs or arching their backs under the showers suspended in the void, washing or drying or perfuming themselves, or combing their long hair at a mirror." ${ }^{37}$

And thus, Calvino evokes the inner quality of seduction embedded in loneliness or in a moment of uncertain vigilance. He writes a city to epitomize the narcissism we celebrate in the shower, or when looking into the mirror, whose walls guards behind it the invisible forest of pipes that helps us cleansing our egos. Meanwhile, whenever Marco Polo writes to Kublai Khan, we stand by Polo at times, by Khan at others, and sometimes by our minds as a third interlocutor. This agency is triggered by the lack of visual imagery in the book, forcing readers to visually render this odyssey.

$37 \quad$ Calvino, Invisible Cities, 49 


\section{Chapter 4: Research Proposal}

This proposal stems from the Black Lives Matter Movement and personal interest on the role of Architecture within street art. In 2020, as the (BLM) Movement took to the streets in the United States, the non-profit organization CyArk decided to "address the legacy of racial inequality in the preservation and understanding of cultural heritage."38 The project called for a community of volunteers and professionals, which I enrolled in. The research was embodied with technique and theory, namely in the fields of street art, photogrammetry, and heritage. A particular unease with street art, though, arose aside from this research. Meanwhile, the agitated and diverse nature of street art presented qualities for research if one would question the ethos of design within it. This unease followed the initial steps in this thesis by questioning "How can architecture reduce the triviality of street art?", aimed at investigating ways for architecture to promote, enhance and actively engage the experience of street art within the urban core.

However, questioning "How can architecture reduce the

38 Hadick, "Map the Moment Initiative" CyArk (blog), https://cyark.org/about/blog/?p=-map-the-moment triviality of street art?" was consolidating architecture external to street art. Meanwhile, as an expression which depends of the architectural settings (walls, sidewalks, etc.), street art could be metaphorically addressed as a "parasite" of architecture in the urban realm. If it street art can is understood as feeding off of architecture, what if we considered the contrary to be true? While reflecting upon the incongruency of this initial questioning, some sequential thoughts tackled the subversive nature of street art. Subversion is defined as "a systematic attempt to overthrow or undermine a government or political system by persons working secretly from within. ${ }^{39}$ In other words, a force operating in the redefinition of a system by questioning the role of its main agents. In this research, with main agents being architecture and street art, the underlying question for the thesis was synthesized to "What happens if Architecture becomes Street Art?". Alternatively, this question introduces an almost telepathic condition between the main agents by nesting one within the other, excluding the reminiscent gap in the previous question.

As mentioned before, street art is inherently subversive in

39 "Subversion." Merriam-Webster. Merriam-Webster. Accessed January 5, 2021. https://www.merriam-webster.com/dictionary/ subversion. 

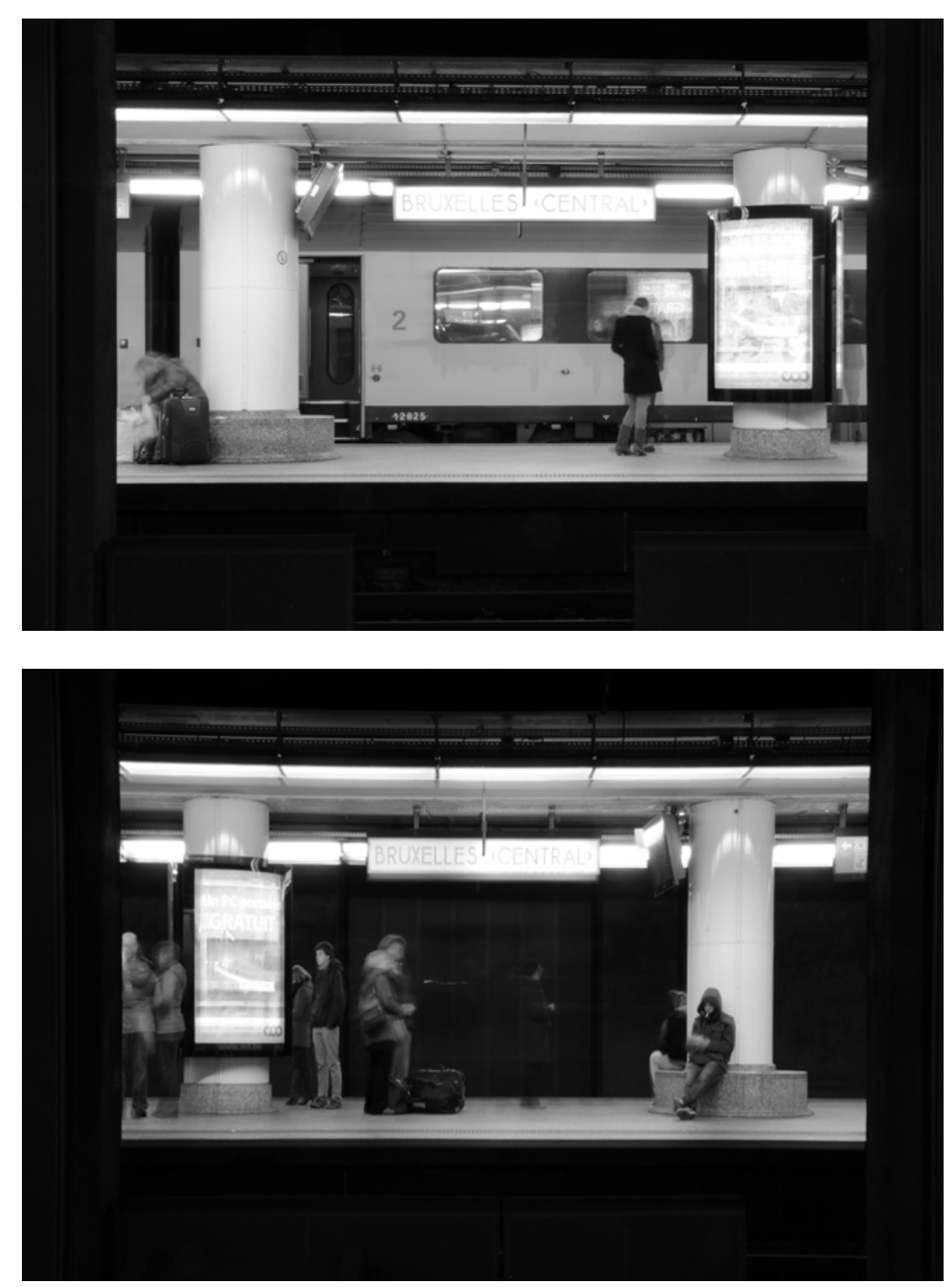

Fig. 06 and 07 - Stephen Fai, subway in Brussels, December, 9, 2012, photograph, Brussels, accessed on October 4, 2020. its nature. It is preceded by graffiti, and understanding the basic commonalities and differences shared among graffiti, street art, and public art enables the comprehension of the values embedded within them. Firstly, one distinction exclusive to graffiti and street art is the questioning of the ethos of ownership through the process of creation and thus the approach of the city from an alternative perspective. However, in graffiti there is no interest in communicating with the public. Its main concern is in creating an internal dialogue within the graffiti community, while street artwork necessarily "dialogues with its context and at times addresses issues specific to a geographical region, yet in its accessible imagery it aims to communicate with everyone." 40

\subsection{Site choice}

The expansion to the world at large in cities is a remarkable character of street art, where the artwork often responds to the emergence of global systems of domination, discrimination, and inequality. This world perception led to an initial impetus of articulating a proposal to enable a larger vision of architecture intersected with street art. In the meantime, "addressing problems $40 \quad$ Waclaveck, Graffiti and Street Art, 80 
of a planetary scale with a predominantly problem-solving attitude"41 would likely dismiss all the scalar complexities involved in street art. As a matter of fact, most literature gathered alluded to the street realm to address the discussion around street art. Nonetheless, it is in this local intersection between the artist, the mural, the walker-by and the landscape, that it is manifested. In other words, it is global as an expression but local in its vocation, assuring the street as both the first and ultimate site of focus.

Drawing from these reflections, the city of Ottawa was chosen for mapping of territories embodied with street art. The choice considered the diverse and preserved canvas of murals in the city. Besides availability, the capital also offers a contrasting setting than those of marginalized areas where murals are often displayed.

"The long-standing image of the city of Ottawa has been aligned with a bureaucratic view of the capital of Canada. Clean, orderly, and safe (...) often seen by the rest of Canada as an orderly, pretty, government town guided by the patriarchal tradition of the federal government," ${ }^{2}$

41 Sarkis, Hashim, Roi Salgueiro Barrio, and Gabriel Kozlowski, The World as an Architectural Project, 2

42 Barthel, "Perceptions of Graffiti in Ottawa: an Ethnographic offering the perfect controlled environment to which street art and graffiti aim at contesting.

Unleashed by Art Jouer, a blog on contemporary art and architecture, an online collection of photographs of murals in the Hintonburg neighborhood triggered my interest. The area, as personally witnessed, offers a lively urban plinth and murals near to each other. As stated in the neighborhood plan "The community is committed to fostering an environment where residents, workers, and visitors can participate in the arts; where artists' networks and creative industries are nurtured; and where cultural workers can afford to live and work." ${ }^{43}$ For the first site visit, the murals mapped were coincidently located in an area being declared as the Hintonburg QUAD (Quartier des artistes/Arts District). Amid an artistic fostered environment, this area was chosen as the site.

\footnotetext{
Study of an Urban Landscape.", 6

43 Neighbourhood Plan Hintonburg and Mechanicsville, 28
} 


\section{Chapter 5: Three-Phase Process}

The Glitch-Visible Cities result from a three-phase process: Gathering, Processing and Conciliating. These processes stem from the 3 streams of research previously discussed: street art, photography and Invisible Cities, followed by photogrammetry explained in 5.2 Processing. Briefly, the "Gathering" consists of a collection of photographs from Hintonburg. These photos frame "adventures", as introduced by Roland Barthes, punctuating the street art (murals) within the streetscape (reflective surfaces, juxtaposed walls, interstitial spaces, etc.). The "Processing" phase comprises the editing and processing of the captured photos in Metashape, for glitch photogrammetric output. Lastly, the architecture discourse - aided by the theoretical information collected so far - aims at conciliating the glitch outputs with written essays inspired by Invisible Cities.

\subsection{Gathering}

Roland Barthes draws an argument on the photo as a "feeling" or a "question", which helps to visualize the instances of engagement with the murals in Hintonburg. He states, "As spectator
I was interested in Photography only for "sentimental" reasons; | wanted to explore it not as a question (a theme) but as wound: I see, I feel, hence I notice, I observe, and I think." ${ }^{44}$ The questioning of wound is a brilliant analogy that helps us to understand how the site investigation of the photographer (spectator) evolved from documentation to punctum photographs. From a generic to a subjective response, respectively. Thus, this chapter primarily illustrates three categories of photos: documentation, studium and punctum.

The following figures $8,9,10$ and 11 are documentation photos. They target the artistic quality of the artwork by capturing an elevation, often frontal, of the mural. These photos inform the visual content without external interferences and represents a technical response from the spectator.

$44 \quad$ Barthes, Camera lucida: reflections on photography, 21 


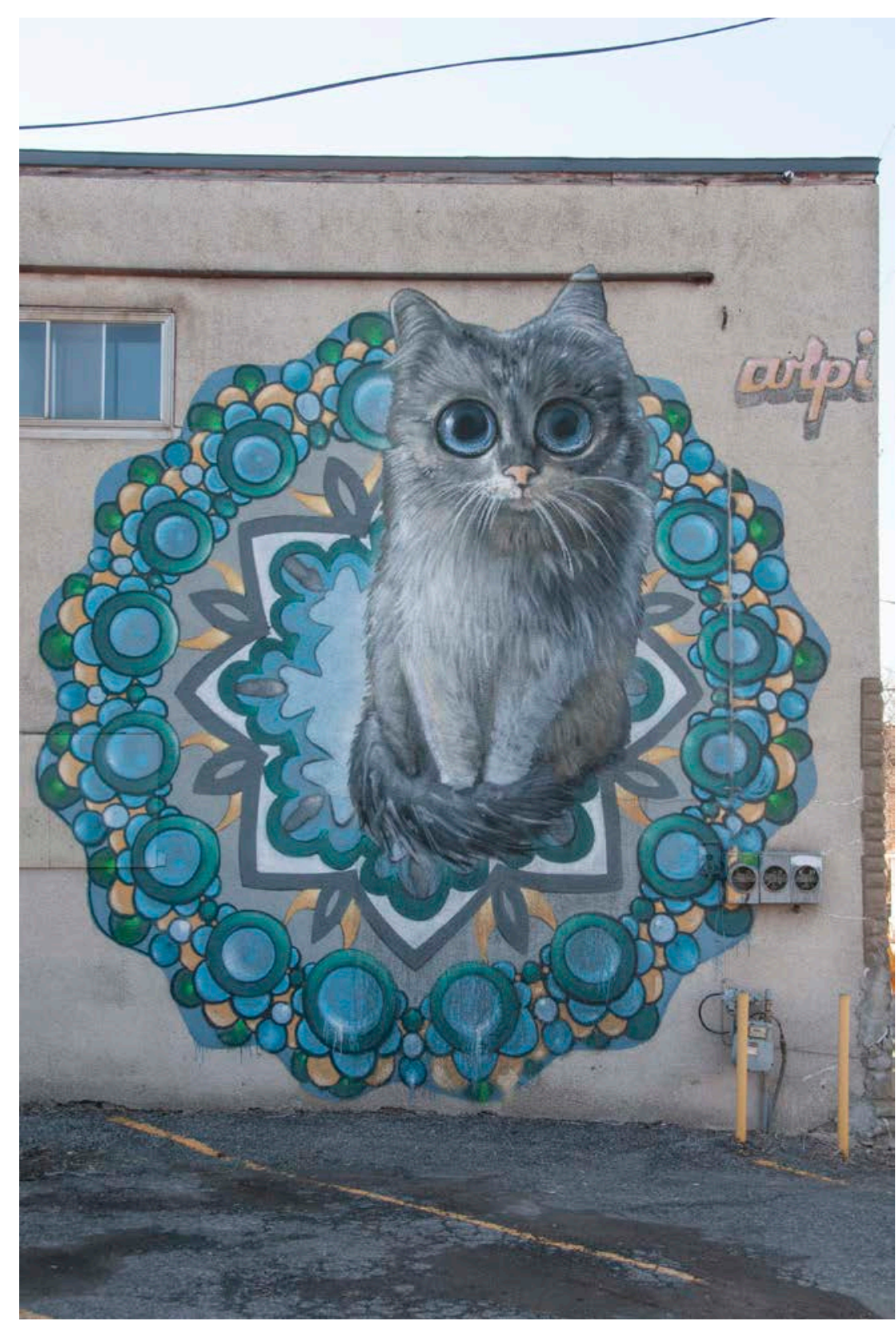

Fig. 08 - Arpi`s mural (cat) 
Fig. 09 - Arpi`s mural (eagle)

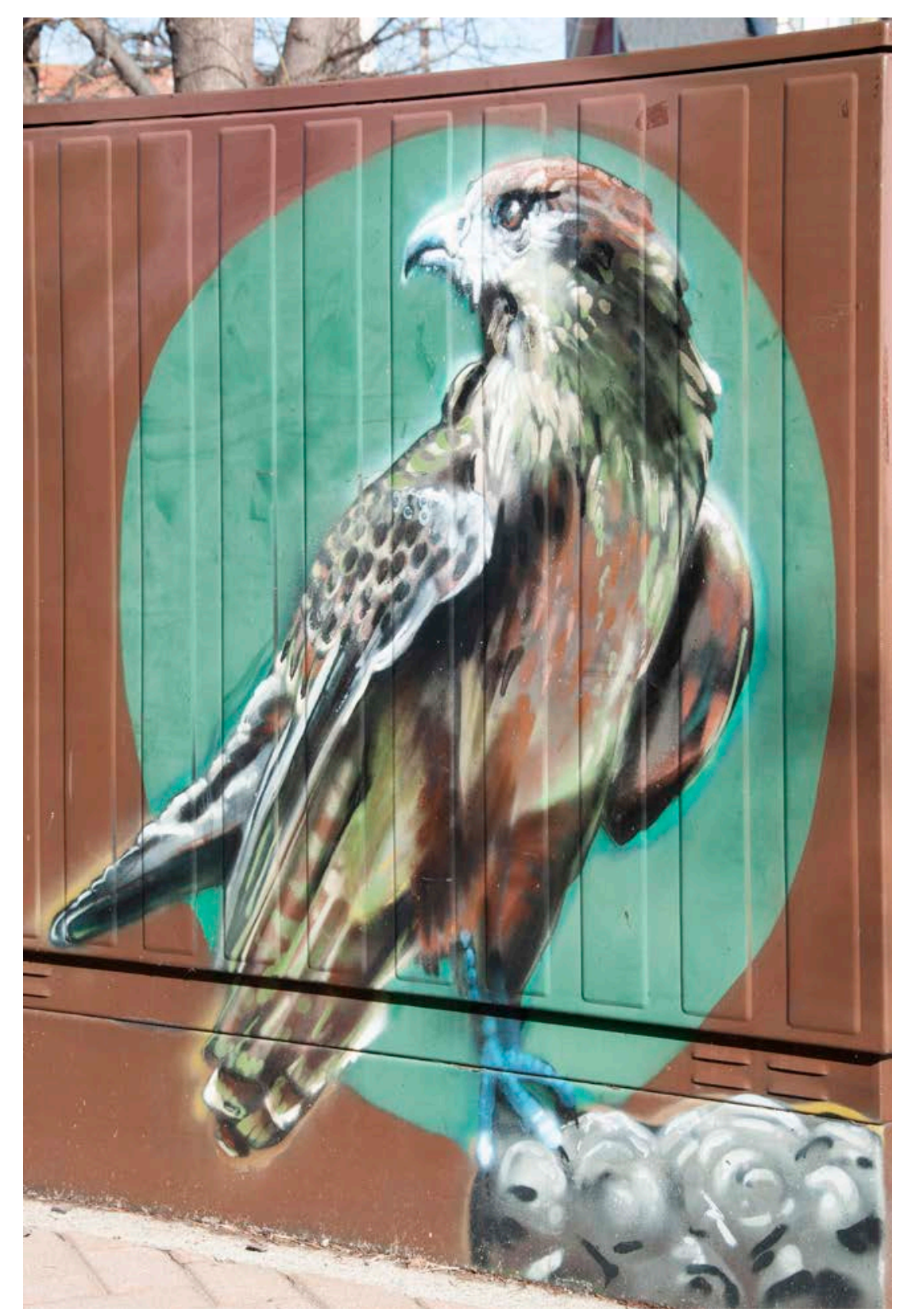




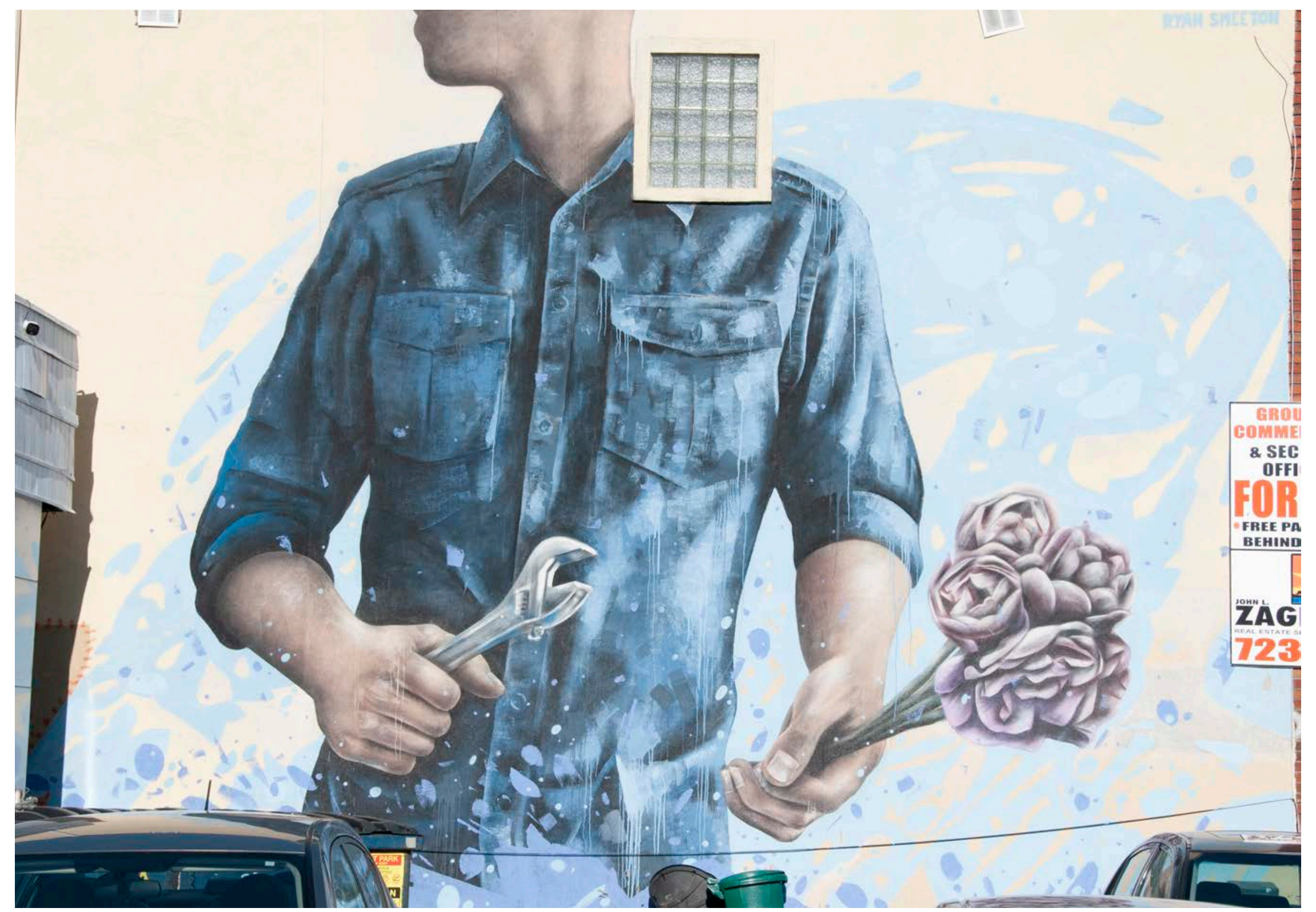

Fig. 10 - Ryan Smeeton`s mural 


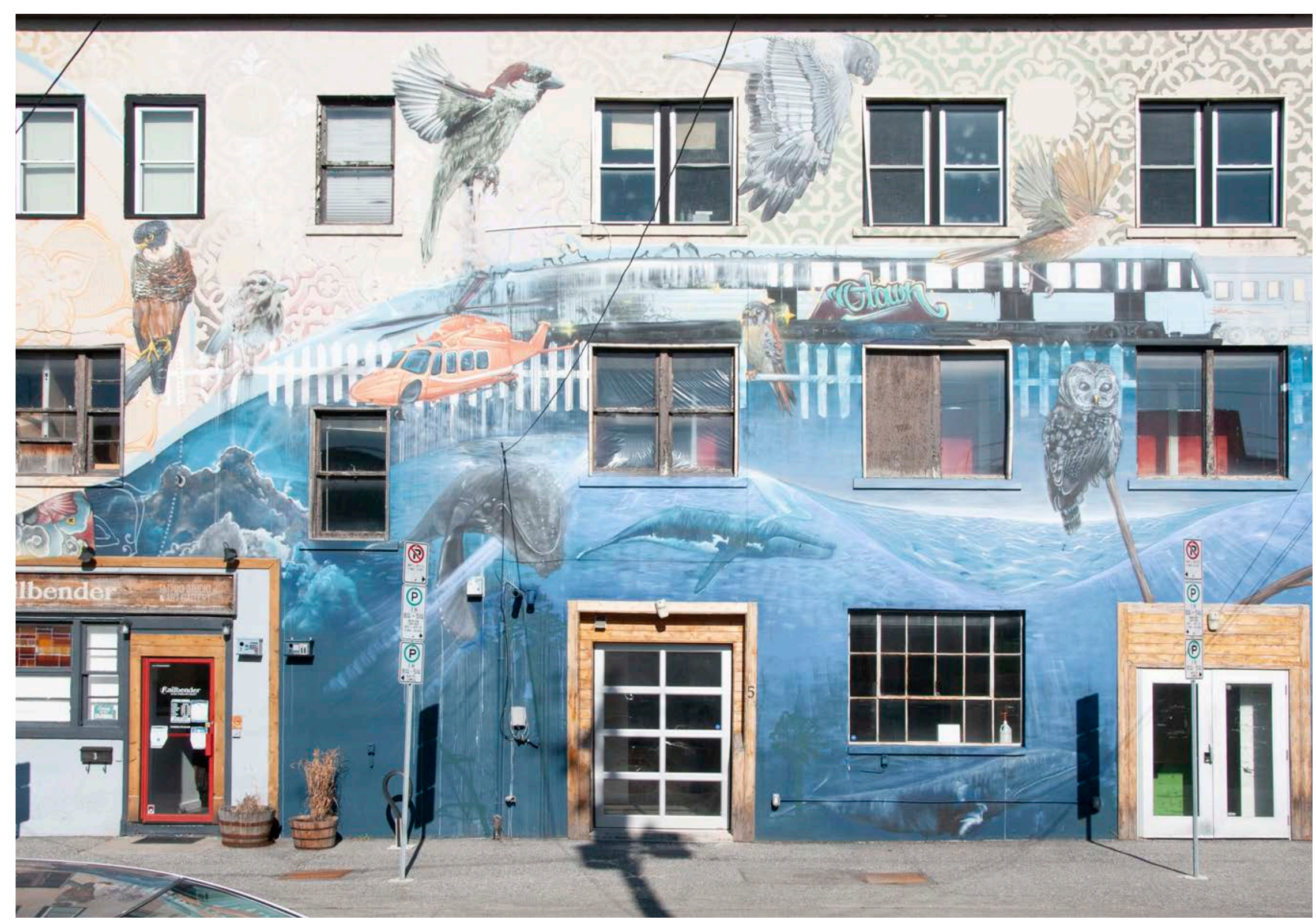

Fig. 11 - Otown`s mural 
Alternatively, a studium photograph denotes some cultural, linguistic, and political interpretation over a photograph by highlighting the mural within its surroundings. Despite some generic tone, the spectator might be able to add some level of subjectivity to the photo.

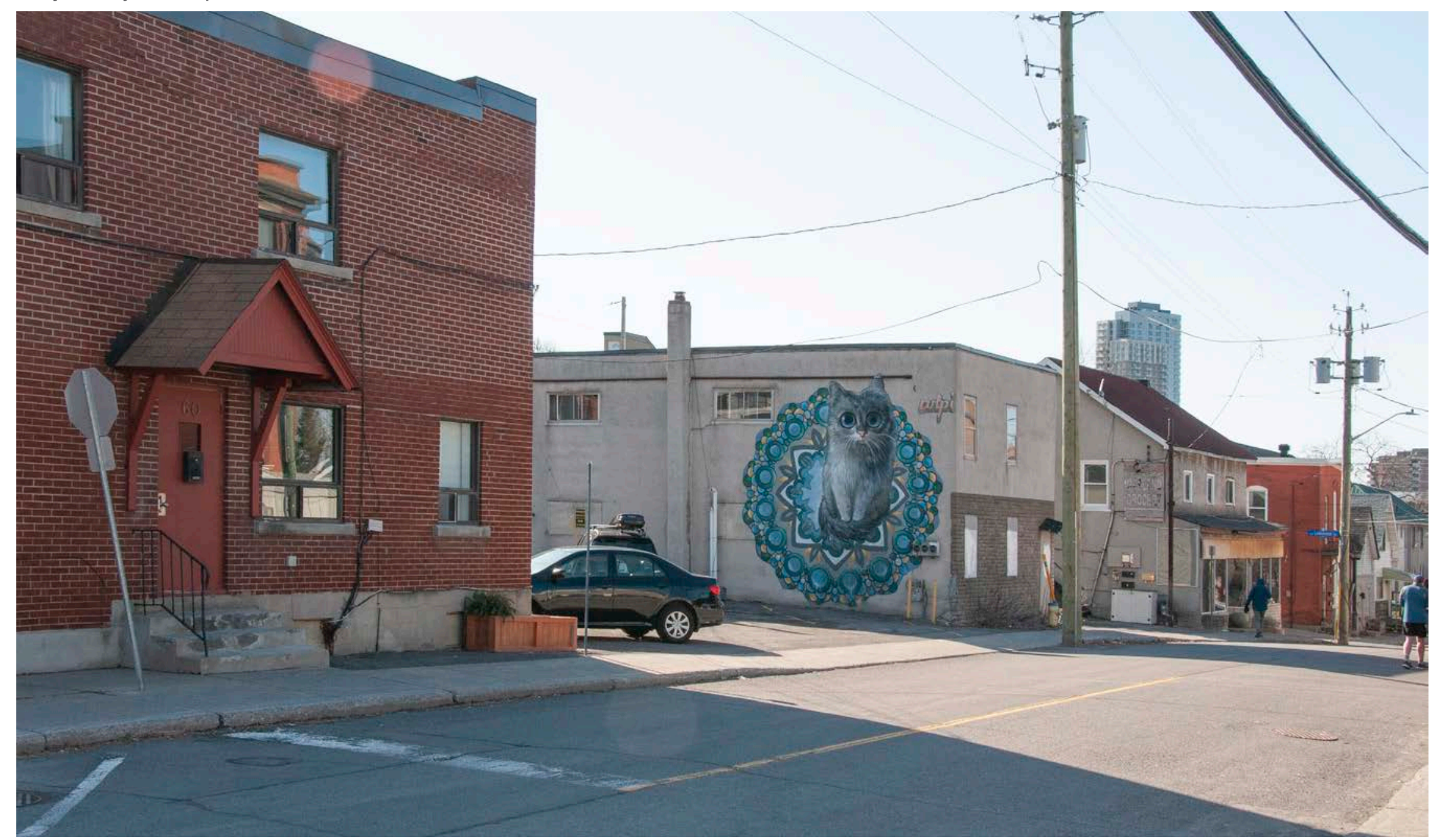

Fig. 12 - Armstrong St. and Garland St; Hintonburg - Ottawa 


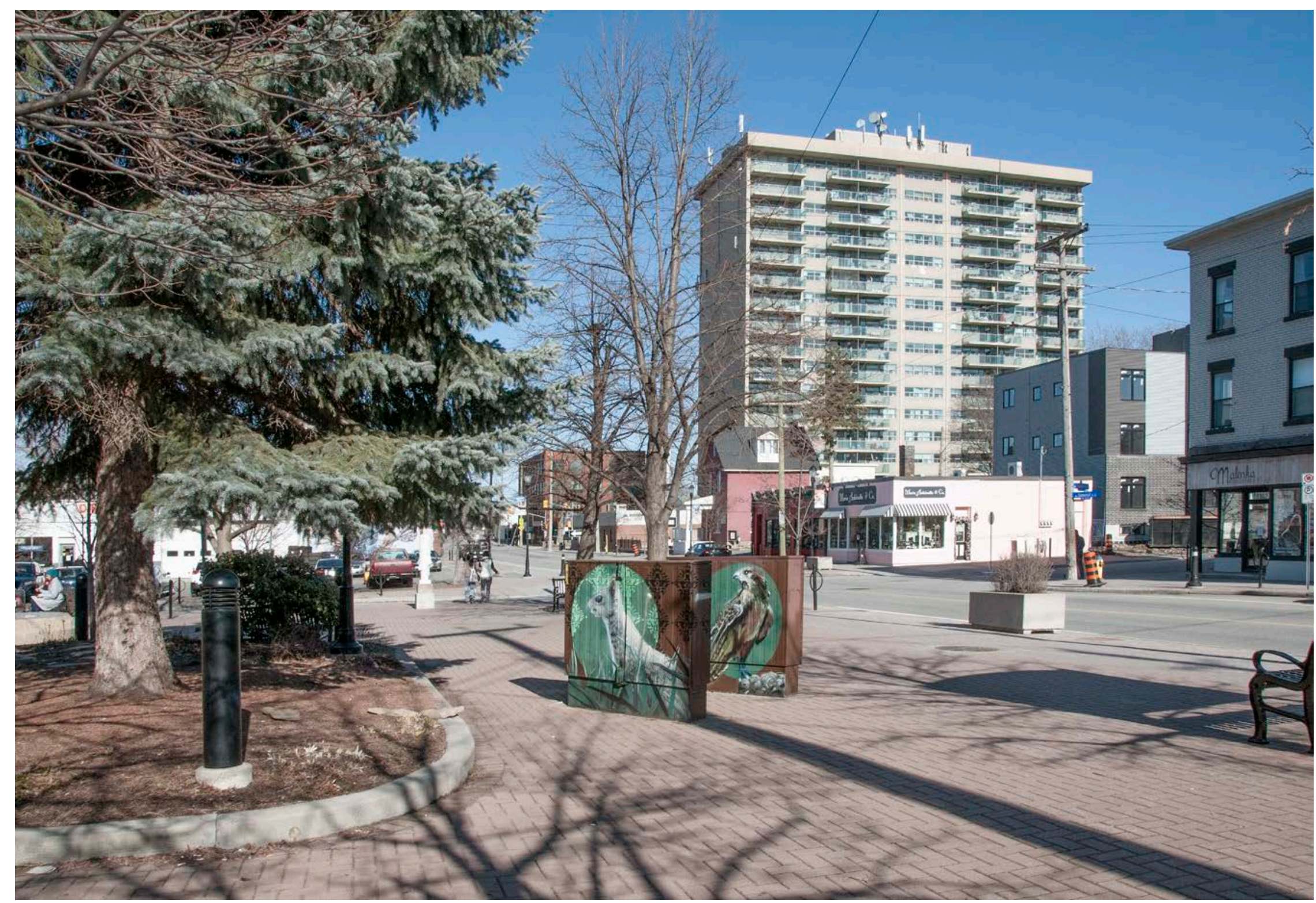

Fig. 13 - Somerset Square Park, Hintonburg - Ottawa 


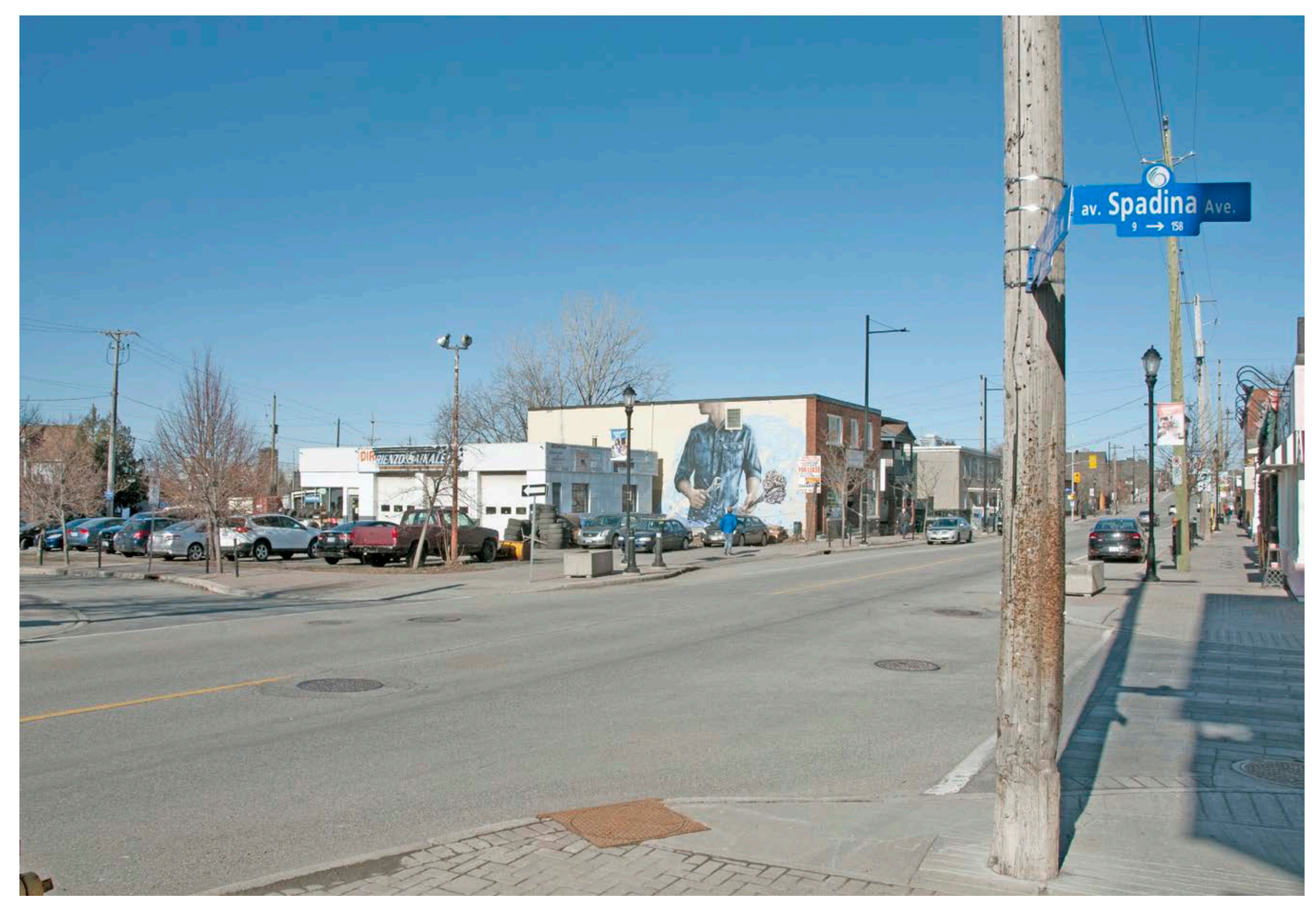

Fig. 14 - Somerset St. W and Spadina Ave, Hintonburg - Ottawa 


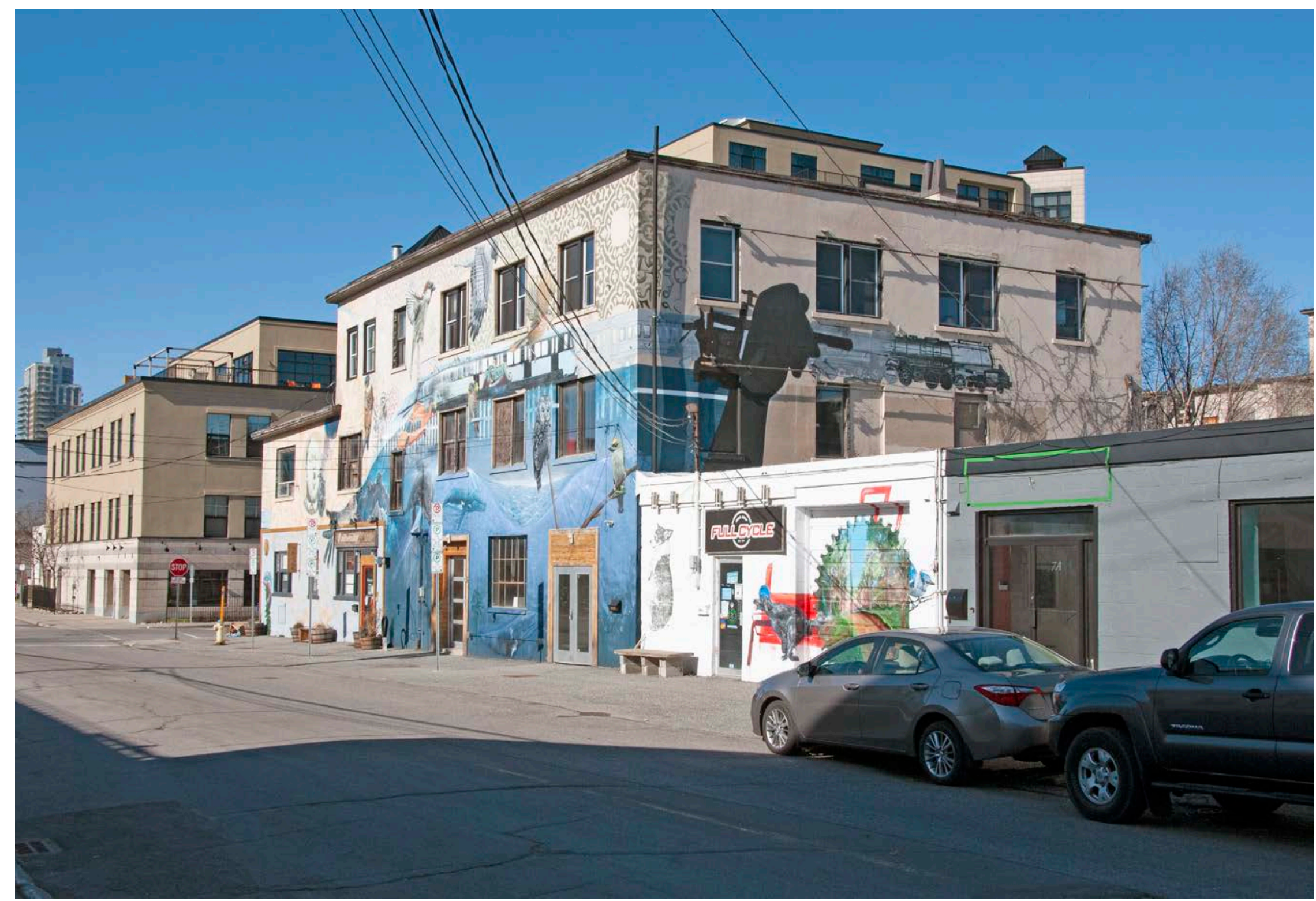

Fig. 15 - Armstrong St. and Hamilton Ave. N; Hintonburg - Ottawa 
Lastly, the punctum photograph. It aims at overlapping the mural with its surroundings, to punctuate an "adventure". These photos relate to Barthes's wound, when the spectator can express the wholeness of his subjectivity by establishing a direct relationship between the object being photographed and the strategic positioning of his eyeball.

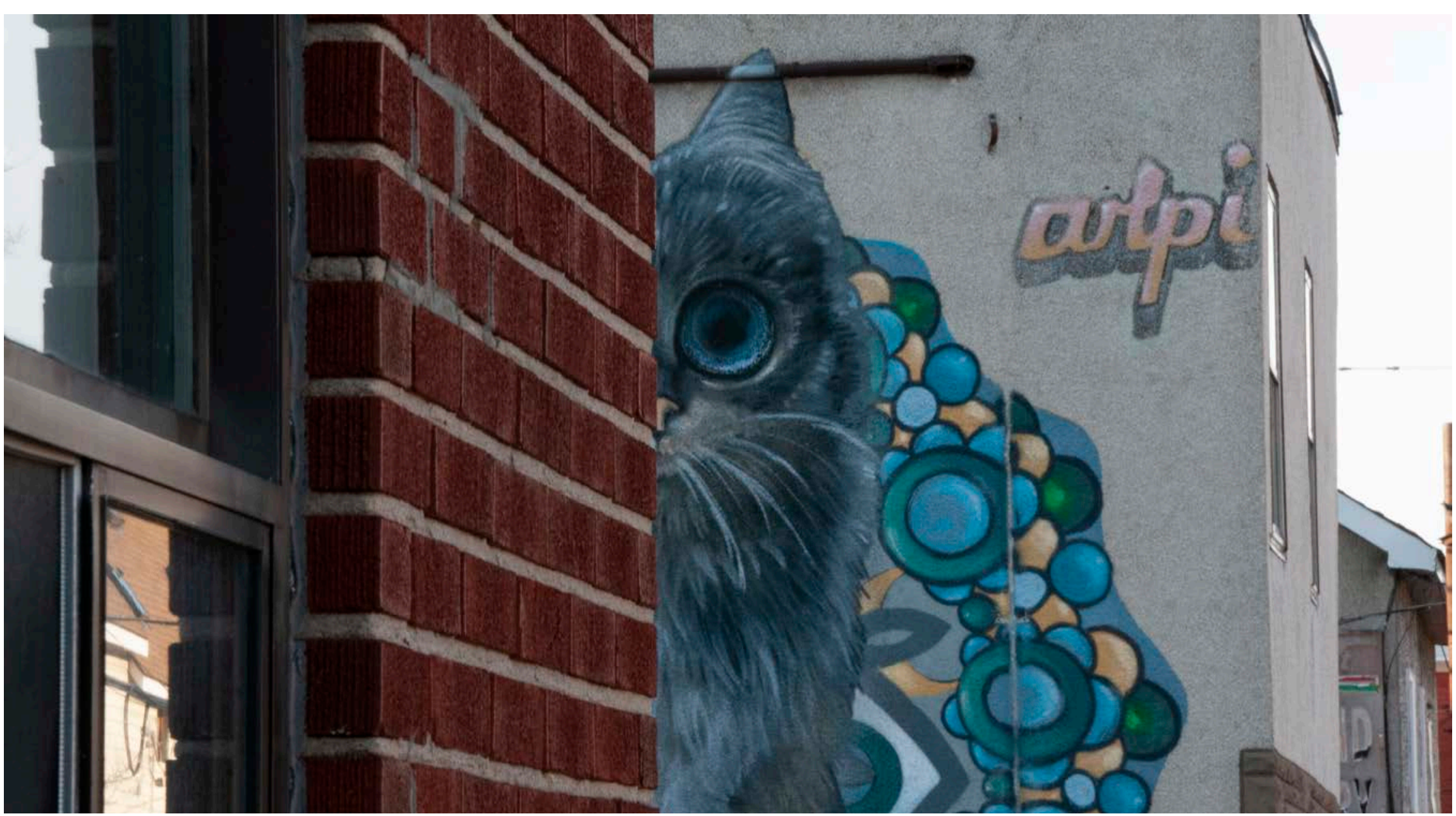

Fig. 16 - Curiosity killed the cat! 


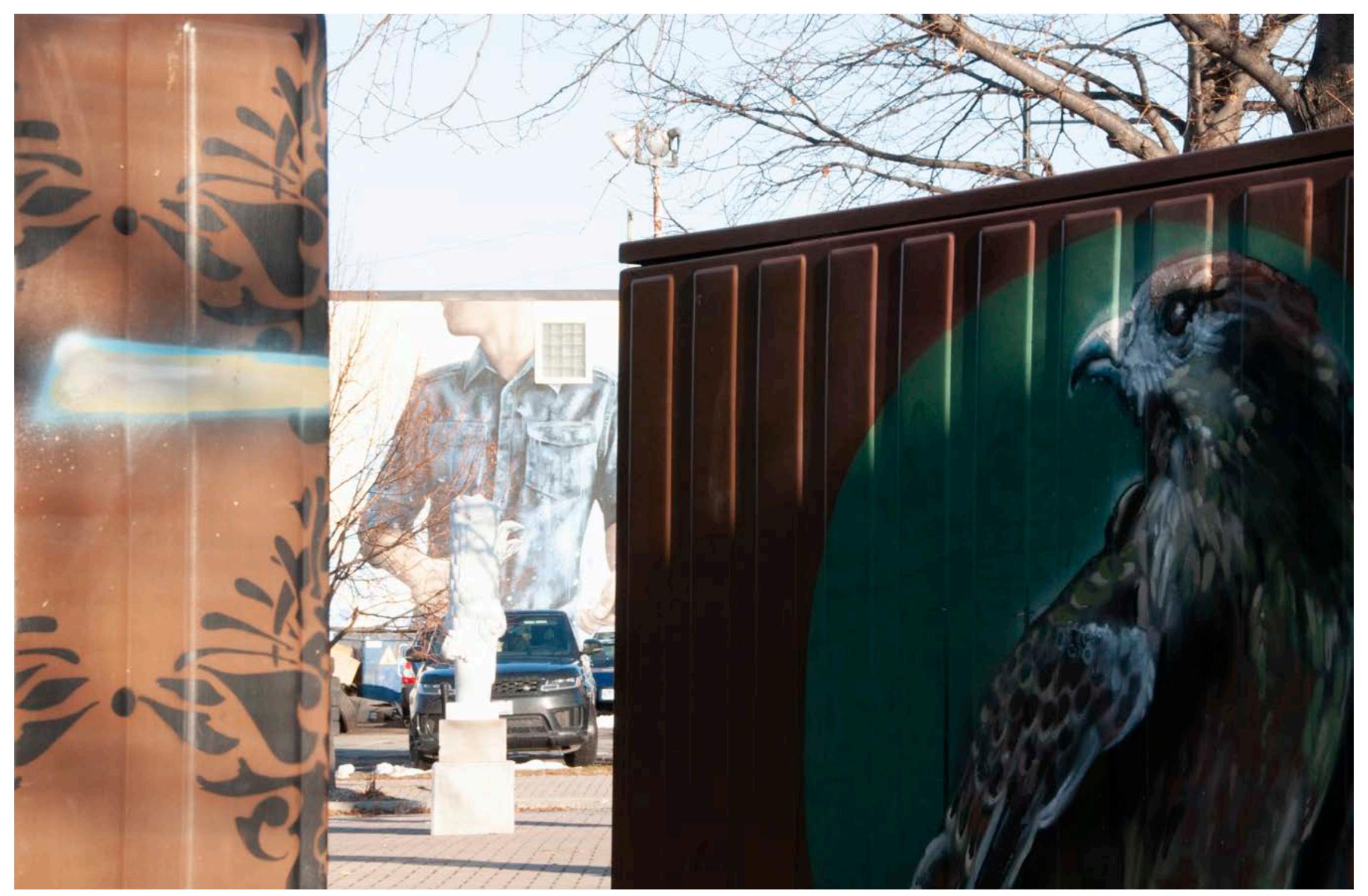

Fig. 17 - Look to the left! 


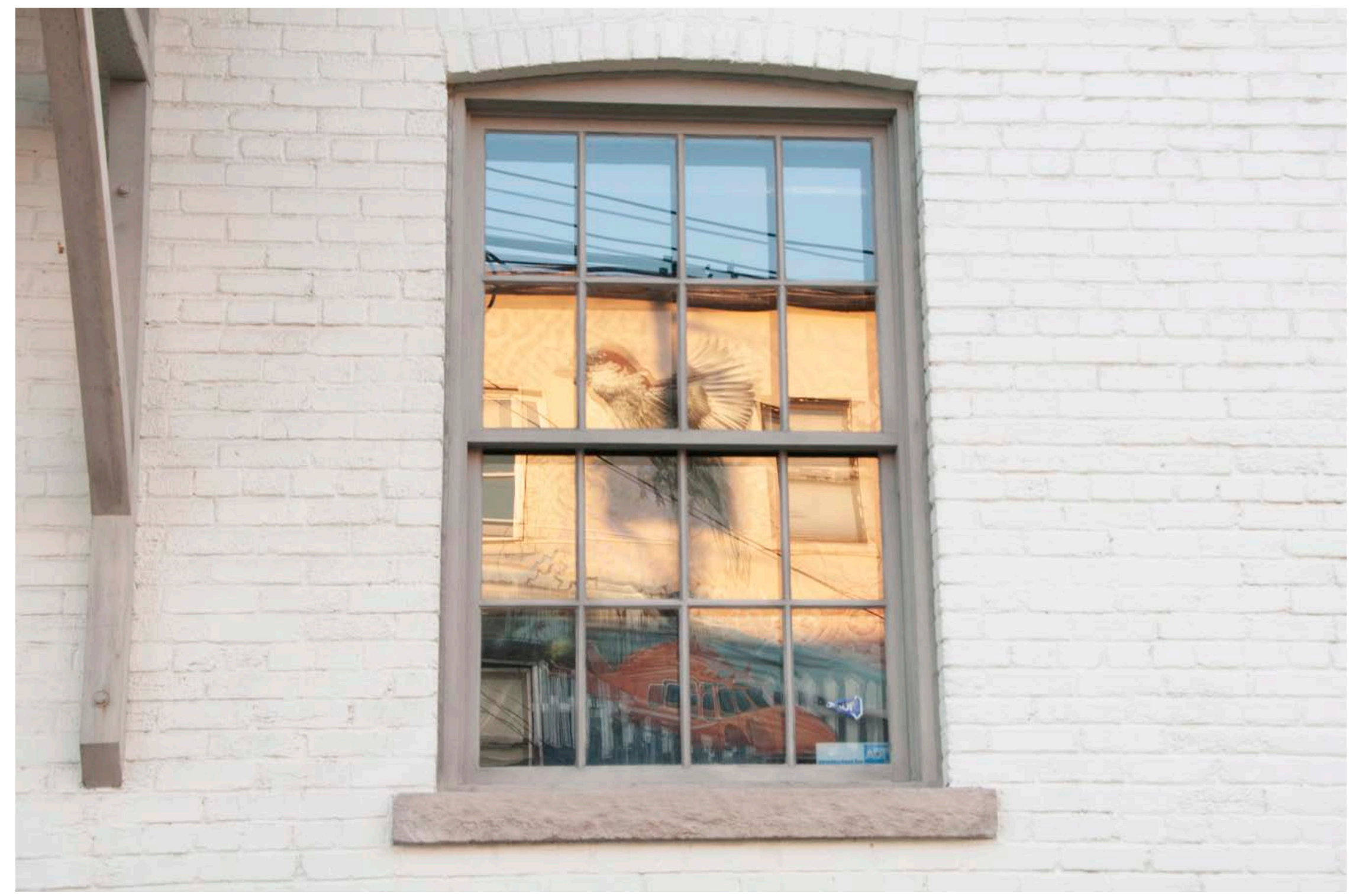

Fig. 18 - Giant 


\subsection{Processing}

The previous chapter analyzed the photo as "feeling", to allow the "adventures" of the spectator to unfold. However, this "Processing" phase relies heavily on photogrammetry, and thus, this chapter looks at the photo as "question". "Photogrammetry encompasses methods of image measurement and interpretation in order to derive the shape and location of an object from one or more photographs of that object." 45 The photographs, meanwhile, derive from an optical process that includes light sources, properties of the captured surface or object, as much as depending on the camera technology used. Additionally, the pixels in a photo can inform radiometric data (intensity, grey value, color value) and geometric data (position in image). Therefore, the primary purpose of a photogrammetric measurement is the three-dimensional reconstruction of an object in both digital form (coordinates and derived geometric elements), but also graphical form (images, drawings, maps).

The in-situ capturing of photographs for photogrammetry purpose encompasses motion around the object -- fig. 19. Thus, the

45 Luhmann, Thomas, Jan Boehm, Stephen Kyle, and Stuart Robson. Close-Range Photogrammetry and 3D Imaging, 2 computer reproduces reality in a digital format by triangulating the photos. However, this thesis proposes an alternate approach to this procedure. In this alternative workflow, the photographer is static and takes several overlapping photographs within the same eye-ball positioning -- fig. 20. Therefore, he captures one leading photograph followed by overlapping secondary photos.

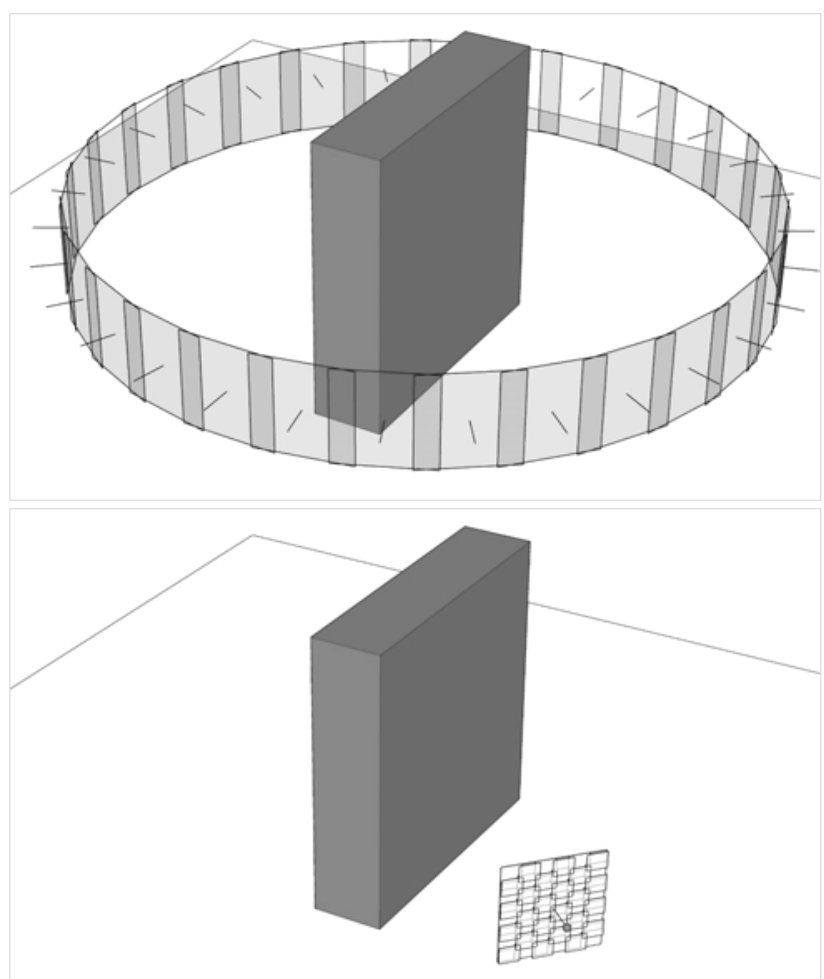

Fig. 19 (up) - Conventional motion around the object Fig. 20 (below) - Absence of motion 
The fig. 21 schematically shows the leading photograph in the background with some of the secondary photos in the foreground -- the fig. 17 "Look to the left!" has been used in this diagram. The leading photograph is any of the punctum photos previously illustrated -- fig. 16, 17 and 18 -- and it must be sharpened.

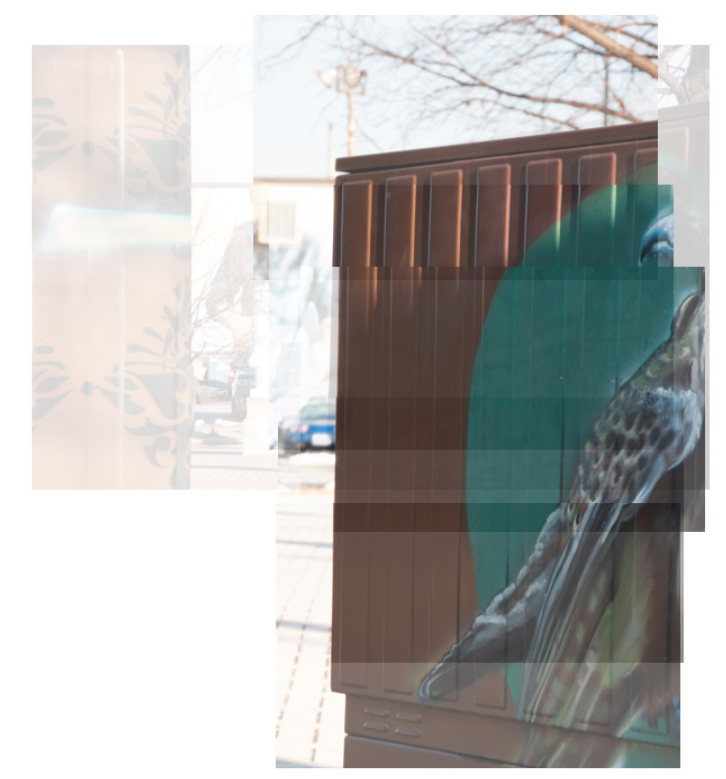

Fig. 21 - Leading photograph overlaid with secondary photos.

In the meantime, the secondary photos can be obtained through zoom manipulation of the camera. Additionally, some blurred area in the secondary photos is expected since most of the captured streetscape has depth. These areas need to be masked in the photogrammetric software -- fig. 22.

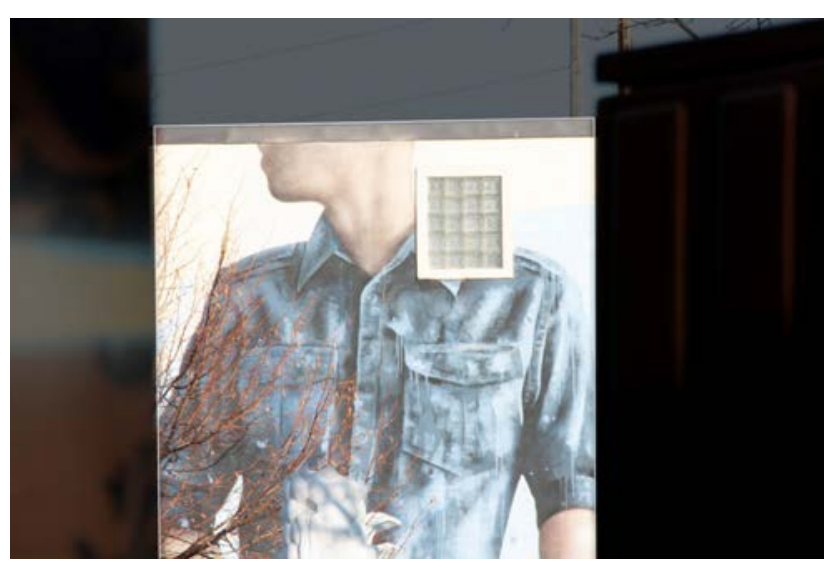

Fig. 22 - Masking of blurred area

Since photogrammetry relies heavily on coordinate systems. the absence of motion around the object in this research causes the removal of the coordinates as known in the real world. Instead, this leads the computer to process the images through alternative coordinates, as imagined by its own programming codes. In sum, a process that leads to digitally aided visual language while arguing for computer imagination. Ultimately, this digital language imprints authorial subject onto a machine, and yet, as Vian imagines, "is also free from the burden of having a past of its own." ${ }^{46}$

Once processed, this photogrammetric manipulation allows

46 Duncan, The OULIPO and Modern Thought, 31 
the relative visualization of glitches on both meshing and texture of the photogrammetric output. Relative in the sense that it reveals the glitch meshing at times (fig. 22), since the geometry does not reproduce the exact same coordinate structure of the real world. The glitch in the texture is equally relative since pixels present as continuous (fig. 23) or discrete (fig. 24) to each other, based on the angle of visualization of the photogrammetric model. For instance, when looking from the original eyeball position, the visual assembly (mesh and texture) is a reproduction of the punctum photo. This, however, changes as different angles of visualization on the model reveal the glitch meshing and consequently the pixels in the texturing as discrete to each other.

The photogrammetric models unfold new voids, blobs, interstitial and juxtaposed spaces. Therefore, this technique introduces potential for additional punctum by adding depth to the photographic lexicon, originally bi-dimensional. 


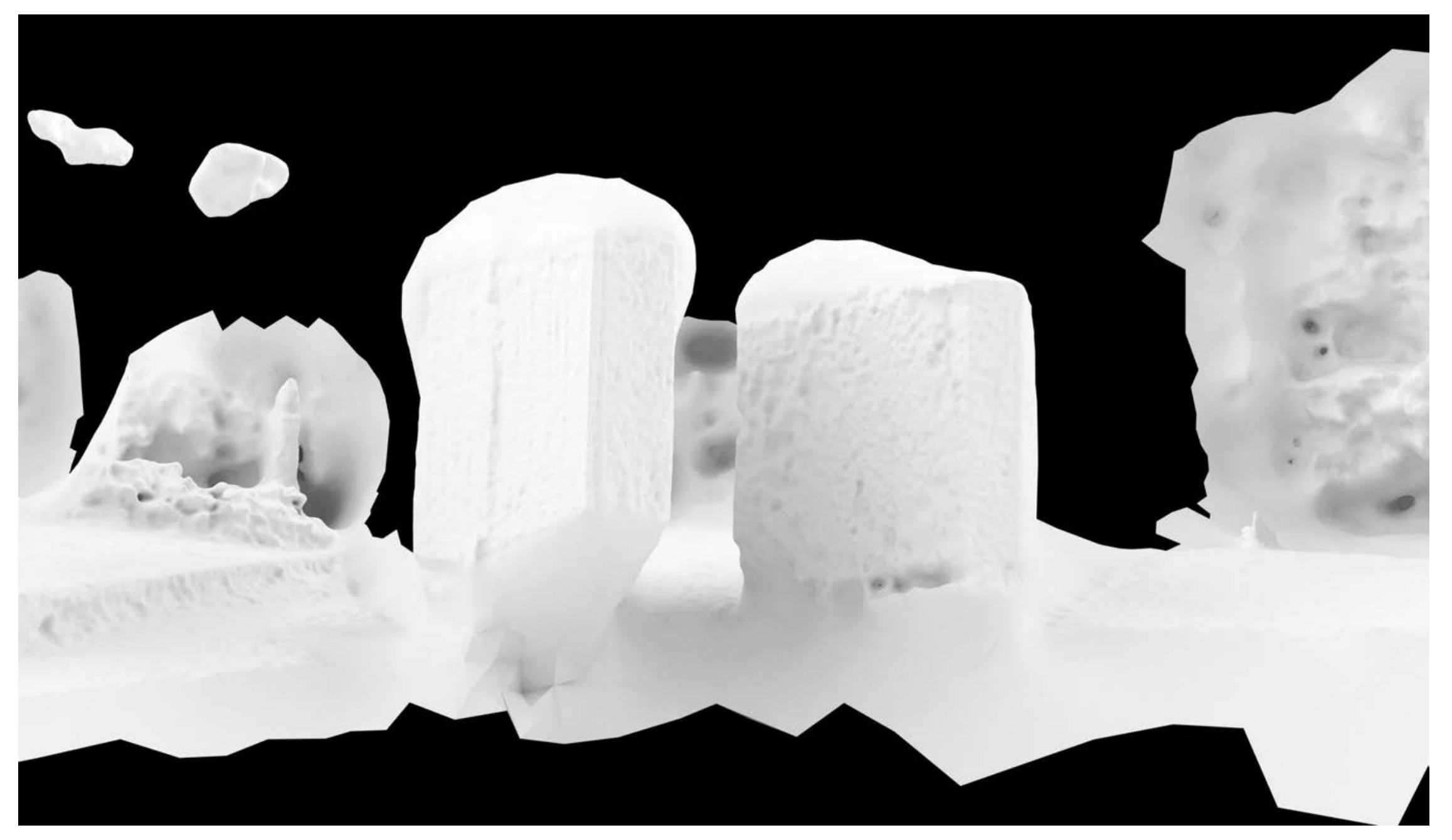

Fig. 23 - Glitch meshing 


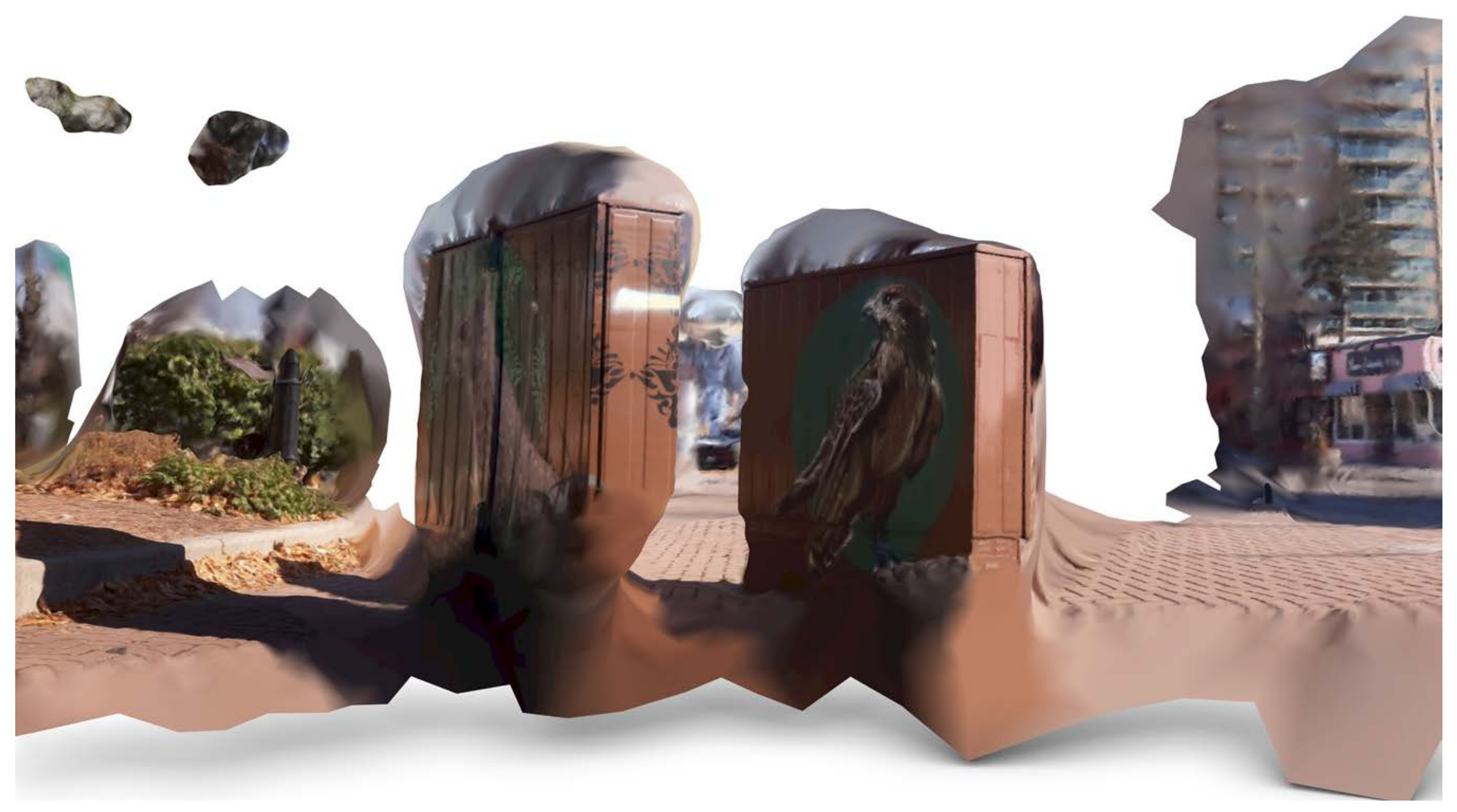

Fig. 24 - Pixels as continuous to each other 


\subsection{Conciliating}

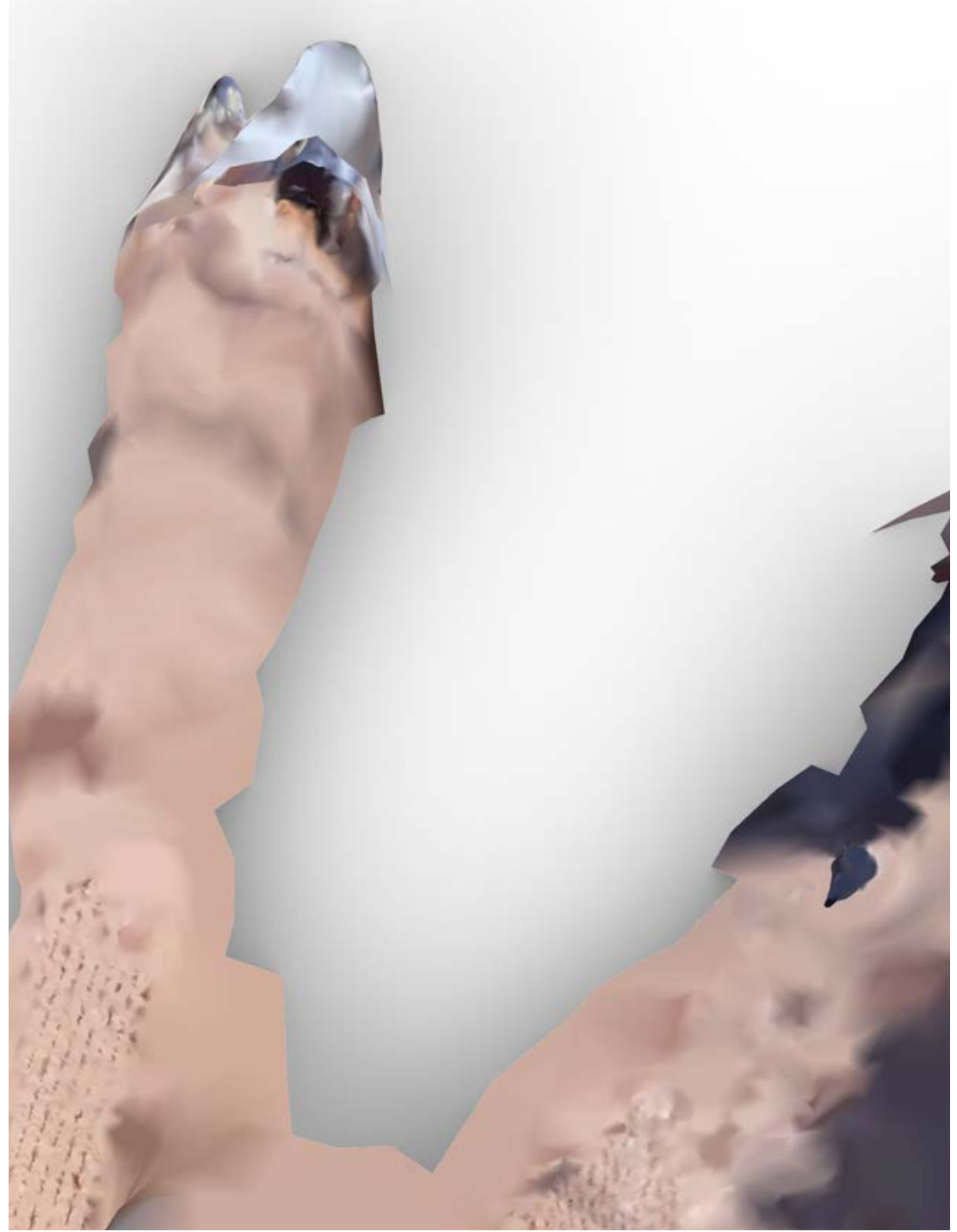

Fig. 25 - Pixels as discrete to each other
Conciliation is any alternative resolution instrument assisted by a conciliator. He acts as a third-party between two divergent ones. This translates into this research through a continuous effort that I manifest when conciliating the written itinerary with the visual one. I read the visual lexicon then I write. Reading and authorial agencies, respectively. A duality which has been anticipated by Calvino. In 1986, he drew an eloquent explanation on the role of literature in Cybernetics and Ghosts. Introducing his reasoning prior to the reading of the fictional essays is a necessary step. It will help to illustrate how the new ways to look at cities relies on the role played by the reader.

Almost ten years after the publication of Invisible Cities, Italo Calvino published The Uses of Literature: Essays. The book opens with his lecture Cybernetics and Ghosts, delivered in Turin in 1968. The essay highlights the role of the reader in the literary journey while inferring an eloquent conclusion to Invisible Cities. It touches upon the relativist position of the reader. Relativist in the sense that surreal environments removed of cultural cohesion, as in the case of 
Glitch-Visible Cities, unleash multiple interpretations on the minds of readers. In other words, Calvino deduces the enzymatic quality in surrealism that discharges interpretative reactions by readers, impacting their agency over reality. This subchapter begins with a brief analysis of Cybernetics and Ghosts followed by a discussion on design activism - as introduced by Martur \& Da Cunha - to argue why Glitch-Visible Cities is a valuable way to look at cities.

In Cybernetics and Ghosts, Calvino draws from a long tradition of local storytellers. He presents two systems of observation: language and reality. He argues for the potentialities of the real world as opposed to the limitations in language. At the same time, he addresses the constant effort of stretching the operations of communication to comprehend reality. A limitation which, ultimately, limits human agency. Thus, he enumerates one resourceless catalogue of available figures from which a traditional storyteller could explore while permutating words:

"The storyteller began to put forth words, not because he thought others might reply with other, predictable words, but to test the extent to which words could fit with one another, could give birth to one another, in order to extract an explanation of the world from the thread of every possible spoken narrative (...) The figures available to the storyteller were very few : the jaguar, the coyote, the toucan, the piranha; or else father and son, brother-in-law and uncle, wife and mother and sister and mother - in - law - The actions these figures could perform were likewise rather limited (...) things that were also classified in a limited catalogue." 47

This discussion on structure and authorial aspects of language, introduces the concept over interpretation. Calvino sees the role of interpretation of the world as "increasingly looked upon as discrete rather than continuous. ${ }^{48} \mathrm{He}$ elaborates by presenting an analogy with the states of the water: continuous interpretation can be gaseous or flow like a river. He describes the discrete as being one made up of separate parts. Calvino, then, provocatively questions "Having laid down these procedures and entrusted a computer with the task of carrying out these operations, will we have a machine capable of replacing the poet and the author?"49 Calvino is aware of the revolution ingrained within this question. Pushing the essay to such an extreme, though, allows him to 47 Calvino, The uses of literature: essays, 4

48 Calvino, The uses of literature: essays, 8

49 Calvino, The uses of literature: essays, 12 
analyze the role of the reader within literature. Accordingly, he affirms "Once we have dismantled and reassembled the process of literary composition, the decisive moment of literary life will be that of reading." ${ }^{50}$ In Invisible Cities, particularly, this decisive moment relates to new ways of looking at the cities.

The role of design is not to see new things, but to see things differently. As da Cunha and Matour observes:

“...we start with a certain design language, such as the way in which we read the surface of the earth, something that designers take for granted. (...) calling attention to another way of reading the land. (...) I'm giving you just one example of a river, but it's the same thing with cities, and city thinking, and the distinction between urban and rural. It's always the urban that is defining the rural. The rural has never defined the urban in that sense. All the measures on the surface of the earth are urban, and some dictate design practice more than we think. So, with 'design activism' we see ourselves as actually challenging the language of design that is in place, challenging the language that is being used to solve fundamental problems like floods which is the same

$50 \quad$ Calvino, The uses of literature: essays, 15 language that has caused the problem of floods. We need a relatively new imagination, and that stems from a new language of the land." 51

In a similar way, it is always the urban that is defining the street art. In this research, however, street art defines the architecture and the streetscape. A subversive strategy adopted in the Gathering phase, solely achieved because of the natures of graffiti and street art themselves. Qualities that, for instance, allowed us to see photography beyond documentation. With photogrammetry and glitch aesthetics we mapped depth within the photographs, while Invisible Cities inspired us to charge digital environments with enculturation of our own. In sum, Glitch-Visible Cities is an act of design activism that helps us to see things differently through discrete pixels and unlikely narratives.

51 Maitiu Ward, Design Activism: Dilip da Cunha \& Anuradha Mathur, Australian Design Review 


\section{Chapter 6: Glitch-Visible Cities: Fictional Essays}

The greatest contribution from street art in this work is that it perhaps draws the intuitive basis in it. Meanwhile, Invisible cities helps to structure the written body of the cities. Respectively intuition and logic, or soul and backbone since the book offers the rigidity of a manicured framework despite the lightness of its narratives. Both forces are manifested internally in the authorial process until they collide with the external force that is the photogrammetric visual lexicon.

The presented literary work is figuratively told by Invisible Cities's original protagonist Marco Polo where he departs into a universe of sprayed canvas and pixels. There, he triangulates digital fragments to unnest the hidden pluriverse virtues of Ottawa and its murals. The essays are framed under eleven cities that respond, each, to the eleven rubrics in Calvino's book. These territories do not frame the exhaustiveness of combinatorial possibilities hidden within the digital and written itineraries. Rather, they elucidate the art of combinatorial plays as the source of creative inspiration that unlocks new ways to look at the cities. 
6.1 City and memory

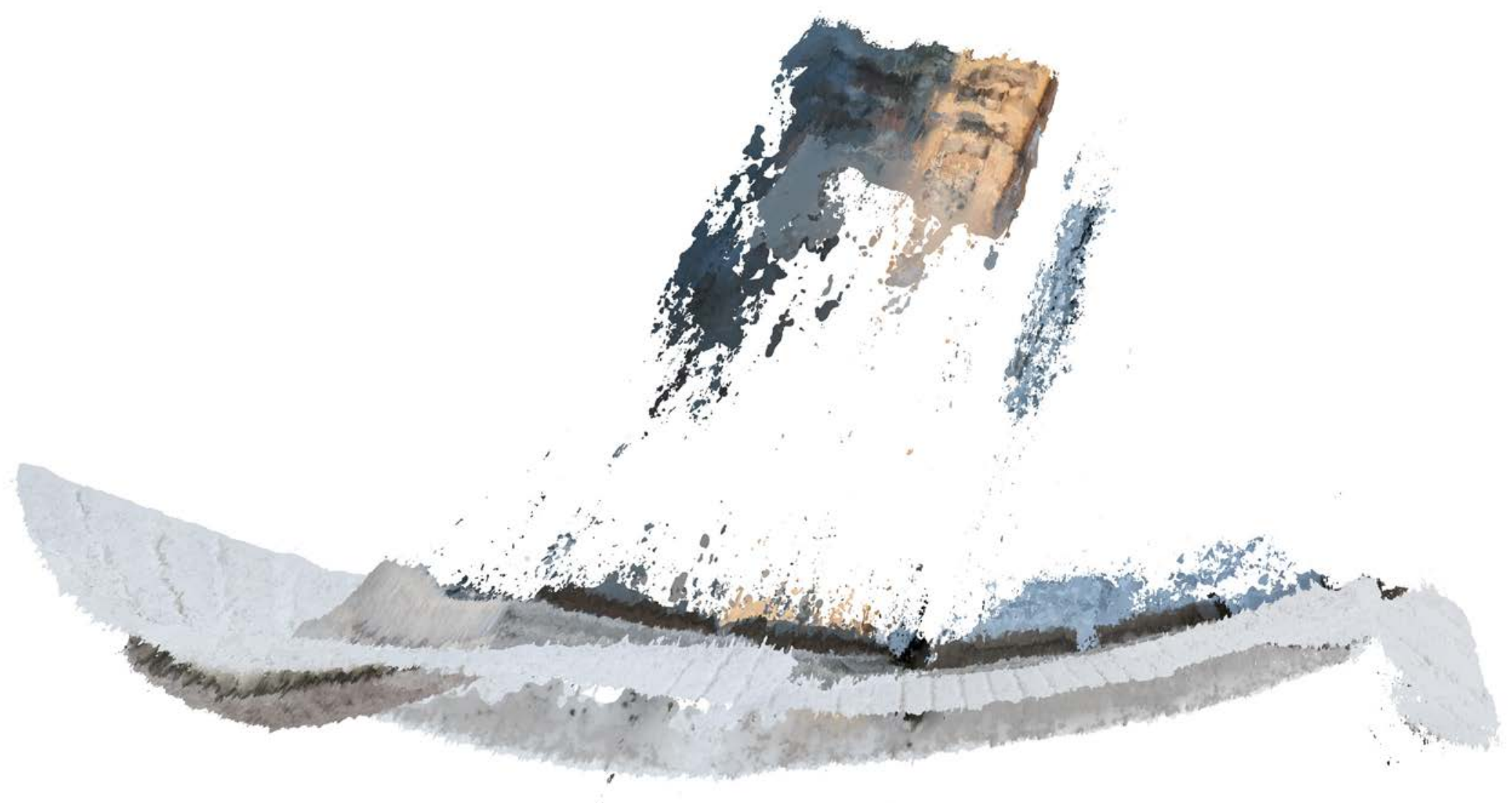

46 


\section{CONTENT DISCLAIMER:}

\section{The following essay is formatted in the present tense since space} and time deforms as we approach the origin of life.

Leaving there and sailing for three days towards the event of singularity you reach BendEden, a city with paradisiac cosmology. It was founded when sinners dared to clash mythical phenomenology in Eden with the singularity of the Big Bang. This event led to the wellwatered plain lands of the Garden to be bent by gravity. Millions of years later BendEden was formed. It contains the Golden Light Falls which begin in the lands of invertebrate sailors and disembogues into the liquid nest.

The upper course of the city is said to be a land of concentric canals that teach sailors the primordial virtues. The canals use a lock system which involves a slow ritual. Briefly, the water rises, the desired volume is reached, and only then, the sailors can proceed. It is a moral landscape that teaches them virtues such as patience, and fraternity, to name a few. Years later they are granted with the passage through the Golden Light Falls to reach the liquid nest. This odyssey of flowing falls is assisted by nymphs as they have a chance to pause and slip into the bubble houses of femininity. Downstream, the sailors learn their final lesson: the manipulation of golden light. The lessons are invested in teaching them the translation of atmospheric language. Only through the filtering of the atmospheric lexicon, sailors will be able to manipulate light. Finally, the invertebrate sailors can depart into the subsequent large-scale of the observable universe. Additionally, white bricks surround the liquid nest. The achromaticity reflects all the visible wavelengths of light from the surroundings, assuring the purity of the learning process in the core. This essay is formatted in the present tense since space and time deforms as we approach singularity. 


\subsection{Cify and desire}

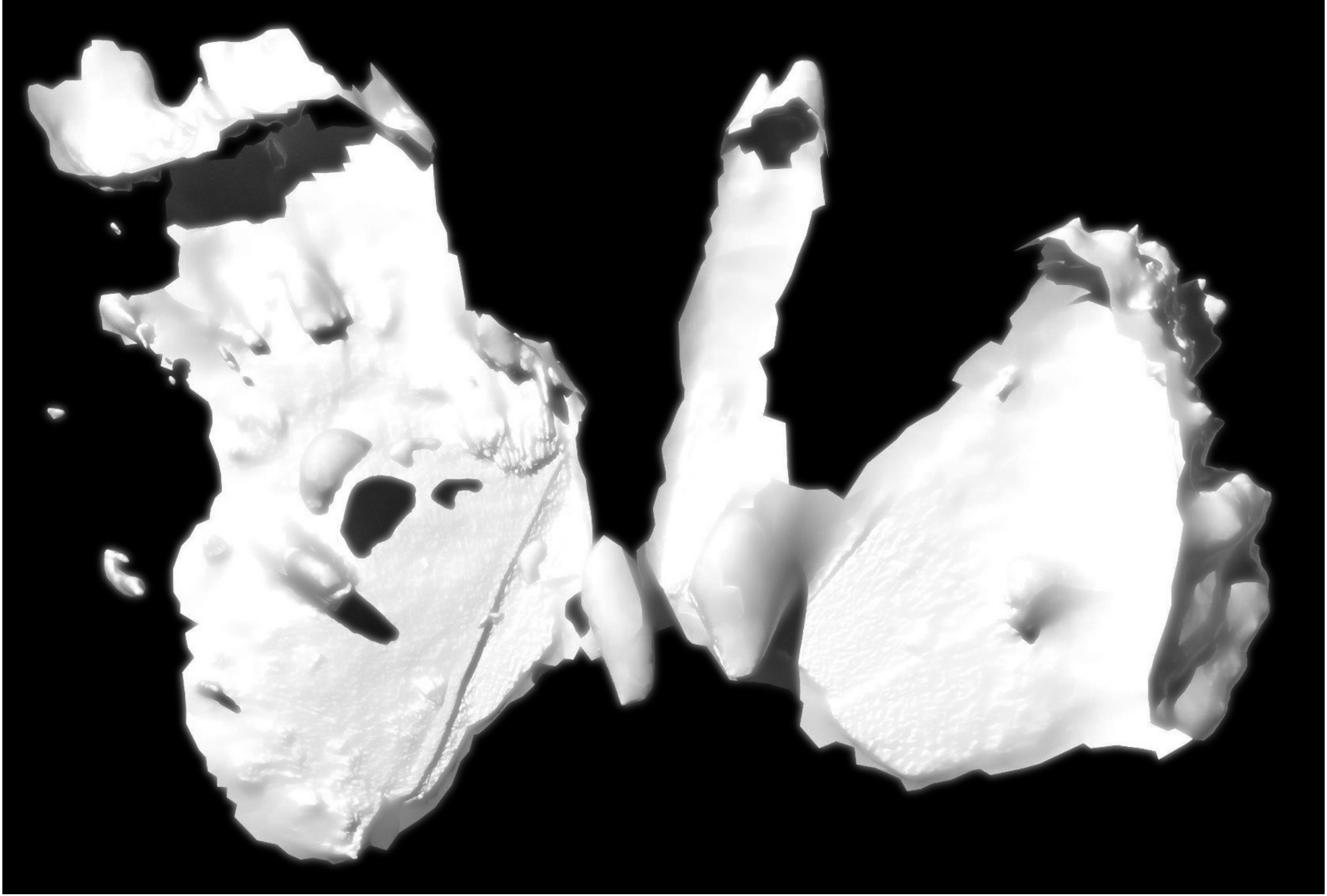




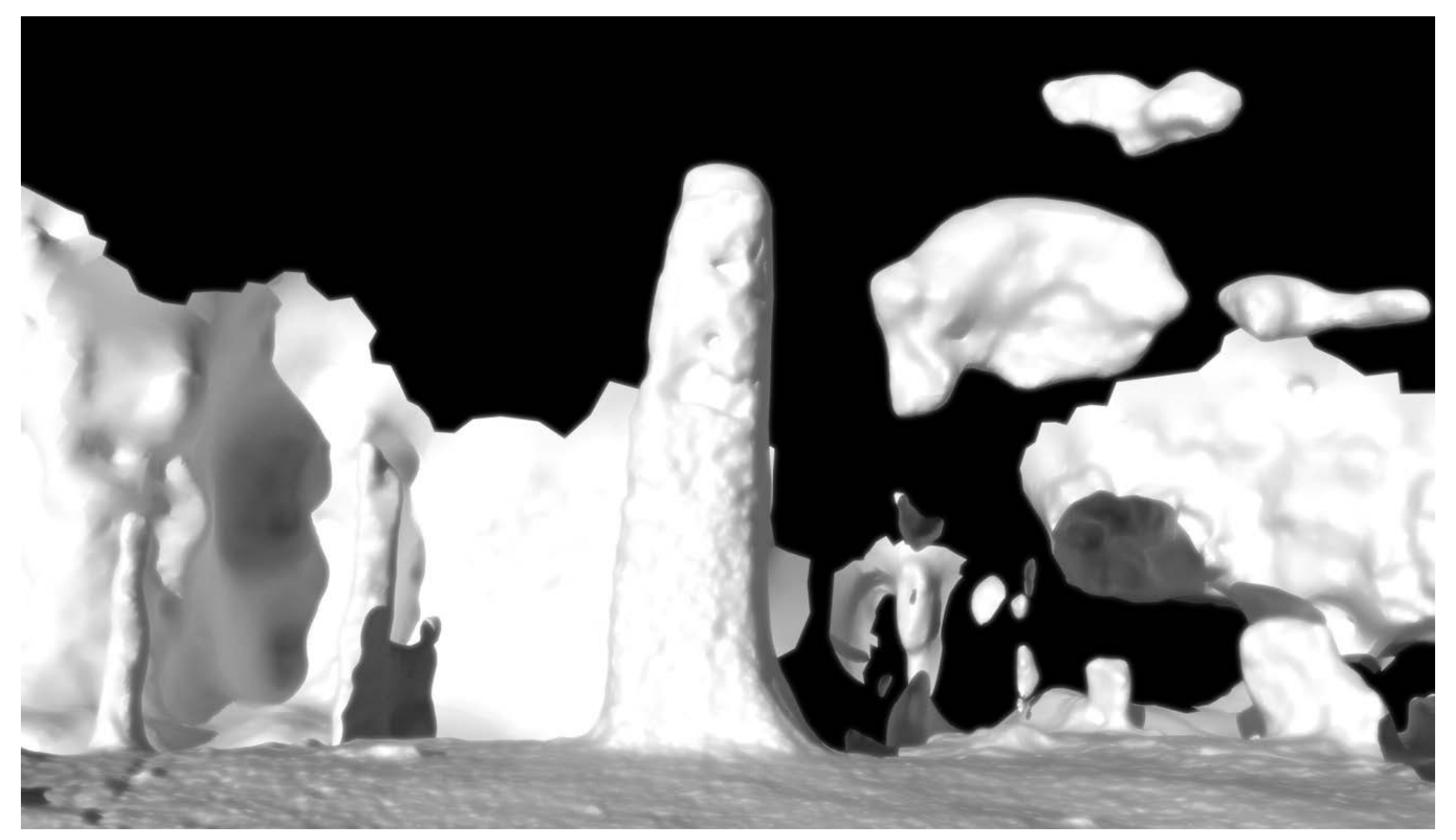


And then, there was the day when botanists understood the day and night phenomenon in CitEY. Accordingly, during the day, colors and texture populate the territory. On evenings, though, all energy needed for the printing of texture is channeled to the "fecundation" of Earth. Botanists were astonished while discovering that fertilizing embodies CitEY`s inner nature.

Over the night, the terrain resembles a reproductive system, organically intersected between female and male genitals. It is symmetrical, with a prominent central structure. The wings become inflated lands seeming to carry the eggs to pollinate nature, while the erected central core fertilizes. Testicle glands replace the eagle at the bottom of the male sex organ, assuring the safe transition of fertilized seeds. Overall, it resembles a remarkable hybrid hermaphrodite system.

In some regions, the edges raise immense walls enclosing the terrain inwards, assuring the interiority of the process while affirming the singularity of life. Yet, the mesh is slightly smooth and inflated at the edges, allowing for enhanced adaptability, and damping while allowing for a greater toleration within incompatible Earth surfaces. Meanwhile, rigor and rigidity in the central surroundings around glands reassures the integrity of the process. 
6.3 Thin City

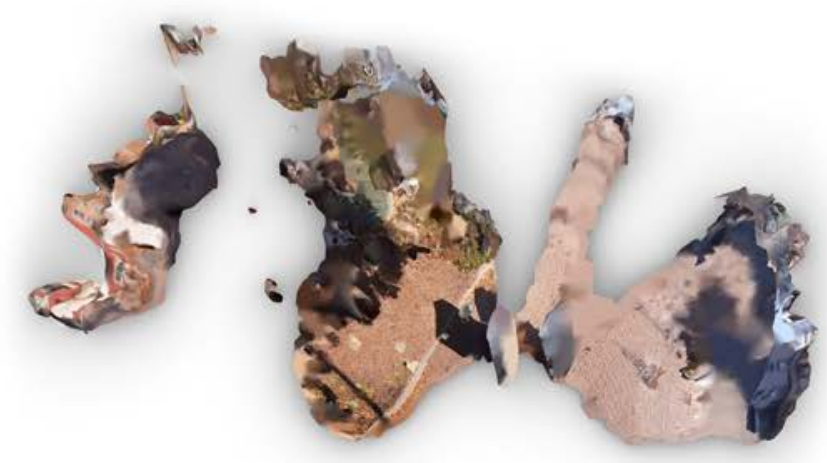

喝
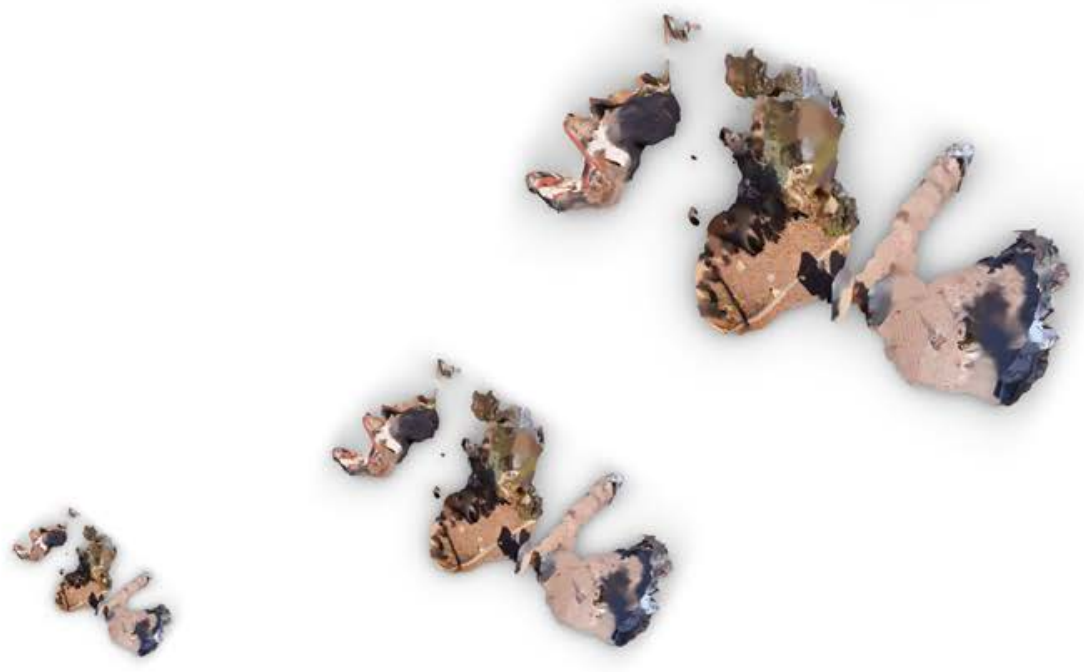
Greater findings came out later concerning the fertilizing nature of Pangea. Through cell growth and differentiation, botanists have also identified a remarkable metamorphosis character within the city, just like butterflies. This process allows the simultaneity of things to arise as it subverts the spectatorial desire over notions of ground and sky. Observing Pangea then becomes an exercise of self-reasoning, where each individual sees it in a particular frame. Some might see towers while others will see the ground.

As wings open around the main core, they seem to carry the residuals of the fertilized Earth territories, like pollen seeming to escape the boundaries of the land. As a matter of fact, in off-gravity territories there is no such a thing as lines delimiting geographies. Lines are too abrupt and literal, and there is no such a thing in nature. In the edges here, the body carries the reminiscences of enclosed cycles. They look much like islands, just like the ones occasioned from the evolving of Pangea. 


\subsection{Continuous city}

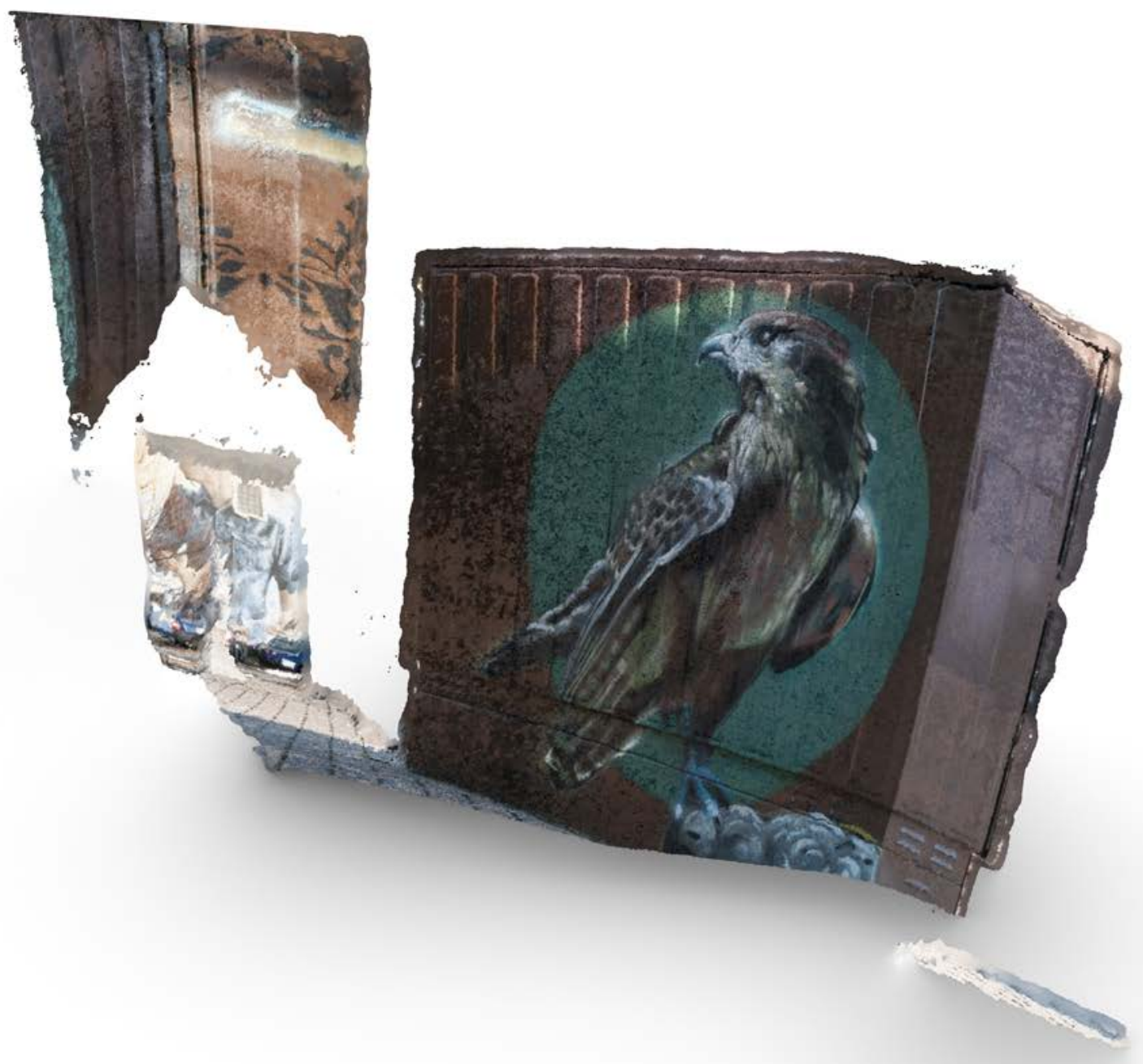


For some staring at a distance, the Eagle guards the land of Synched in the foreground while the Man is depicted in the background. Eagle and man resonating each other, vigilant, looking at the same direction. As we get closer, though, the foreground and background switch to conceal the true territory`s identity. The man seems to occupy the forefront while the Eagle animates the background. Yet, for some, they stare to the left, while for others to the right. For instance, if one stands perpendicular to them, they might even look down, or up. With notions of depth being defied, any cartesian assumption in Synched is ever invalid. Therefore, there is no horizon, no before or after. Time here is not even sequential, but rather simultaneous. You shall move around to seek your truth, while nature and geography rest still in the terrain assuring the ultimate permanent quality in Synched, the meaning of vigilance. Here, the citizens do not adhere to cartesian principles, they rather prioritize the essence of the message over the angle of approximation.

Few other minor details animate this landscape. A lightyellow blueprint caused by the Eagle case shading over the Tribal case. It resembles a rusted ray of light onto the metallic surface. This transformative decay is to remind people of endurance, temporality, and the ephemerality of life. Yet, a thin "ligament" attaches the Man`s body to the Eagle, as a message of fragility. 
6.5 Hidden city

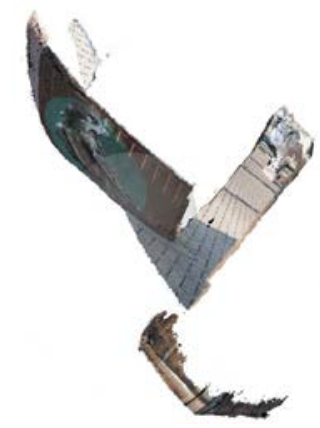


EPAGRÝPNISI is the encrypted entitlement of a city in disguise. It was deciphered years ago by nomad graffiti writers, whose names remains unknown. Much like the culture of graffiti, the encoded nature of this territory aims at internalizing the dialogue within the city territory. If writers were to establish any territory, it would most likely be a camouflaged terrain much like EPAGRÝPNISI, silent yet transformative.

This city guards us from invisible hazards, as reported. A territory able to silently operate the observable and tangible realm (Earth), while "calibrating" it. A peel becomes the permanent scar tearing apart an Eagle from a Man, remembering its inhabitants' pain for not being in resonance. The Eagle guards the city while the man wearing jeans holds a flower and a wrench. The flower represents the encrypted germination for moments when the city is reduced to its "landing" silhouette, a tree branch. In times like these, its inhabitants germinate nature around the world. Meanwhile, the wrench represents the balance from EPAGRÝPNISI when calibrating the unease on Earth. An off-gravity terrain whose body fluctuates in air much like the hovering of an eagle, while landing in disguise on trees at other times. A nomadic behavior attributed to the remarkable organicity and mimicked silhouette of its territory. 
6.6 City and eyes

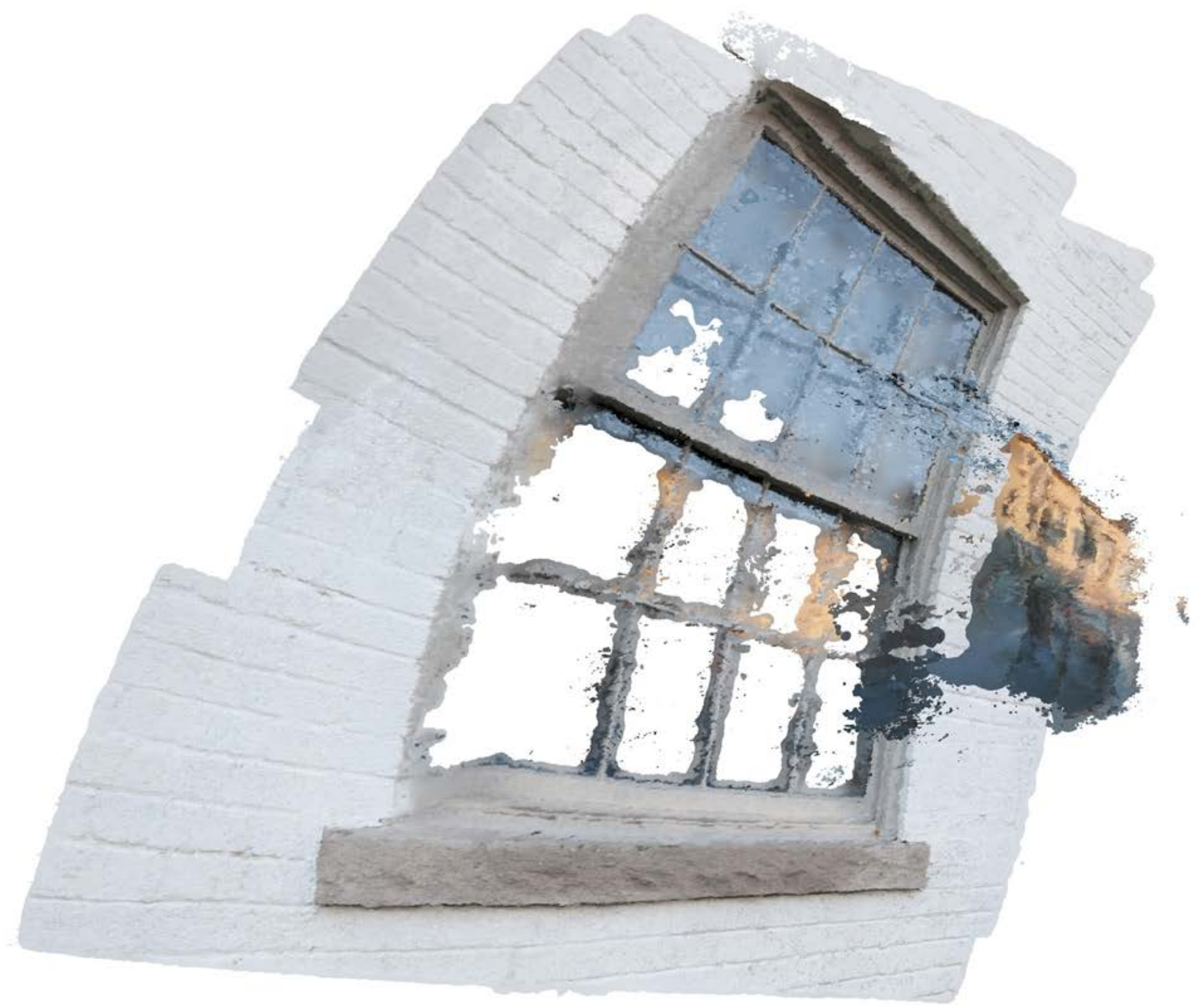




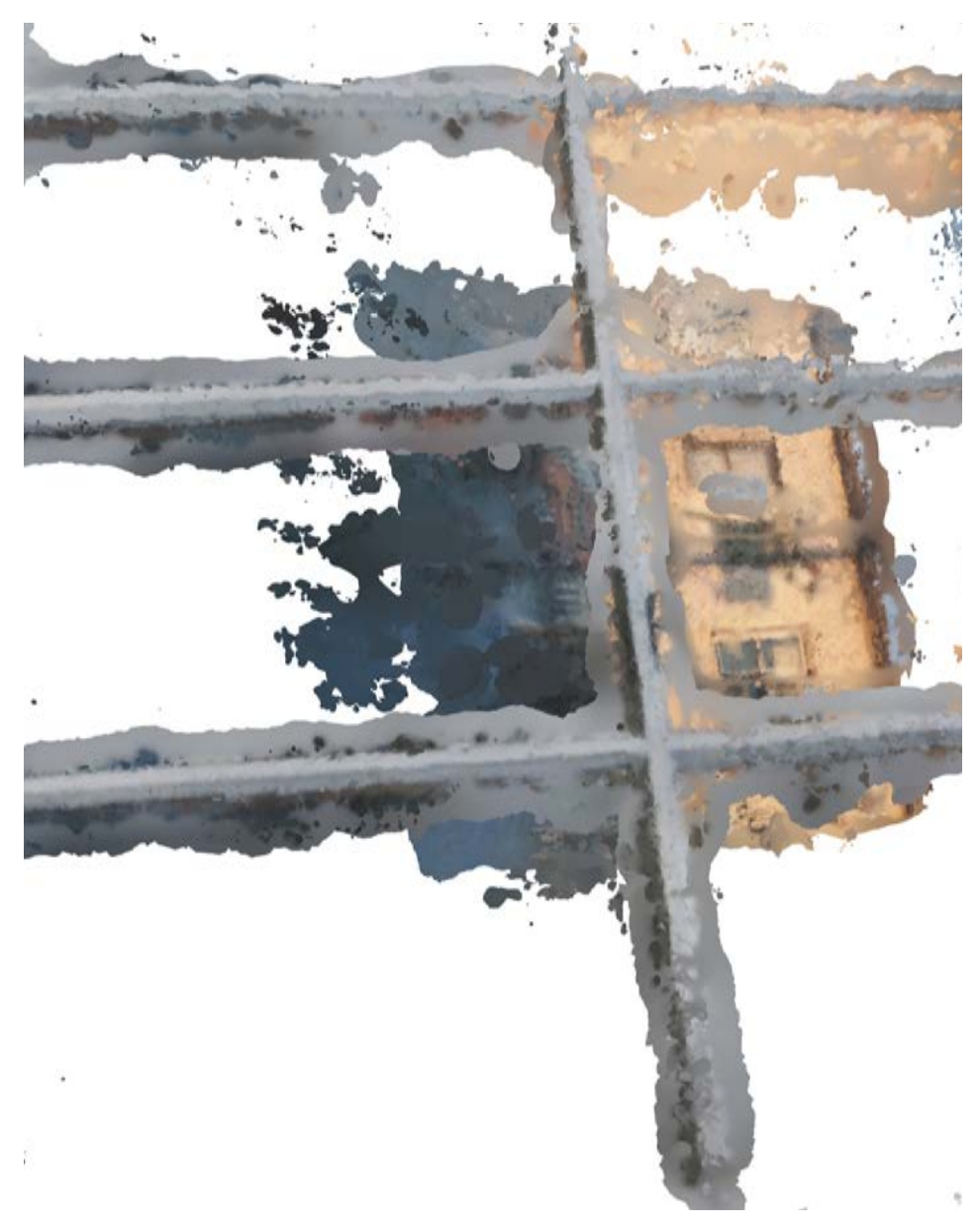


The people from Antzzzena share this primitve tale of the curse of reflection. For thousands of years they have been building their cities to map reflections. In present day, the whole territory is covered under a system of antennas. These receptors are disguised in the window`s mullions and are granted for every single habitant. It allows for buildings to expell or absorb reflections. For instance, if your office overlooks a church, and you find yourself under stress, you can opt to absorb the silence and meditative state of the church. However, you might also age according to the absorbed reflection. This is the curse. In this case, if the same modern office overlooks a gothic revival church, you might not want to "revive" its meditative state of being.

Antzzzena is seasonally imersed in brainstorming architecture. At times like these it usually reflects the lightened tales of passing by cars, traffic lights and the asphalt as your eyes look down at it. On another solstice, the architecture is rather sharpened, giving depth to the stare. Reflections are less delusional and more clear. Not too easy, so you will not loose interest, nor too hard so you do not give up. Flowing, at ease. However, Antzzzena can not escape the magic in the reflection that alters the scale of things. For that reason, the tales also speak of concave and convex planes that gave origin to giants and dwarfs.

The city is an ode to the windows which are so trivial, invisible, yet so present in our ordinary existence. It is an ode to the windows through which we observe, starre, wonder, think, brainstorm and tap the ashes of a shared cigar. Windows behave passively and silent in the active transformational role they play in our lives. By ackowledging "sentiment" to windows, Antzzzena has unfolded the spring within architecture. There, buildings seem to dance the primaveral waltz of absorbed and expelled reflections. A melted illusion used as an artifice to help mitigate moments of stress, loneliness and excesses too. But ultimately, Antzzzena teaches its habitants with caution since the blossoming of the spring is also a reminder of age. 


\subsection{Trading city}

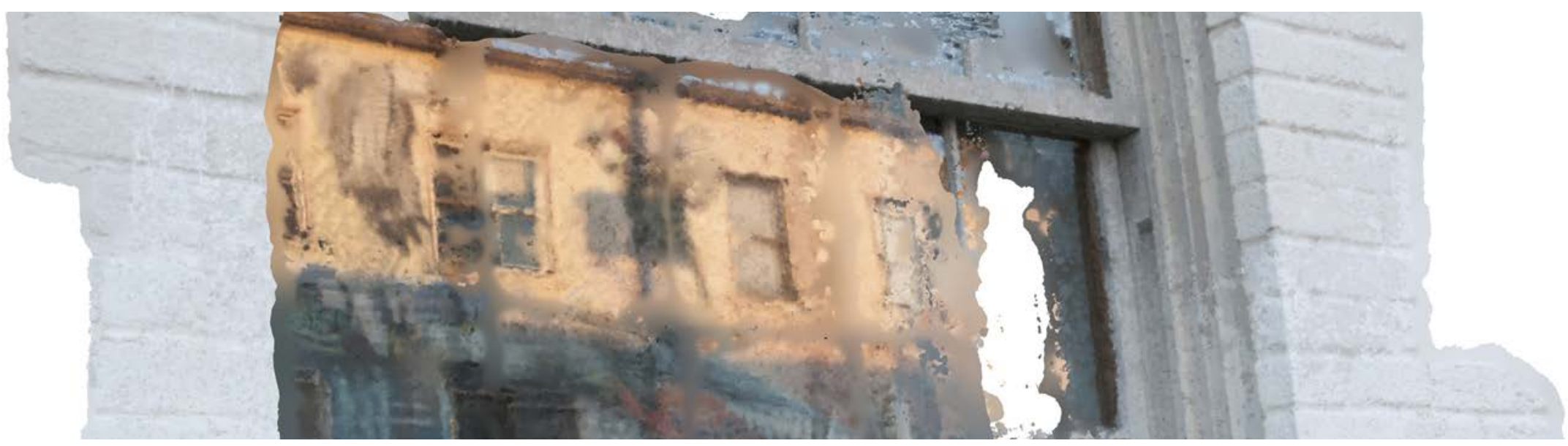


You do not come to ESPILCE only to see humming cats, but also to watch feline birds. Predator and prey coexisting in the phenomenon of backward eclipse. This city is embodied with two satellites orbiting each other. Additionally, a central-force of playfulness links the permanent exchange of their inner qualities.

As the eclipse casts the vacuum of a satellite onto another, it resonates the primordial chase of all, that of the light and the shadow. The ritual, as followed, alters both the land of the midnight cats and the golden humming birds. As the eclipse retrogades, all streetscape embedded in both lands changes. It unfolds hidden air tunnels of hurricane and palaces of wrinkled paper floating in the lightness of forests of arboreal clouds. They help reducing the acquired shade of neurosis received by the land of the midnight cats. The golden land of humming birds also gains greater adaptability towards "beaky" mapping. Throughout the duration of the eclipse, the birds might "sniff" around their streetscapes to kill their inner curiosities.

Meanwhile, the cats intonate the humming quality from the birds. The continued echoing guides them to a state of elevated production at first followed by meditation. Throughout the backward eclipse, cats can jump backwards, or even optimize their rightization reflex to 10-15 times per second. Consequently, the land of the midnight cats is a natural setting filled with domesticized bamboos. The lighteness of the forest cushions the landing of the cats. Collectively, though, they build a musical instrument whose reverberation echoes the humming, until all citizens are induced to a meditative state of mantra. This ofen happens by the end of the retrograde eclipse. By then, tales will sway in the indigo of the midnight land, and wings will flap in the golden one. All is back to normal. 
6.8 City and signs

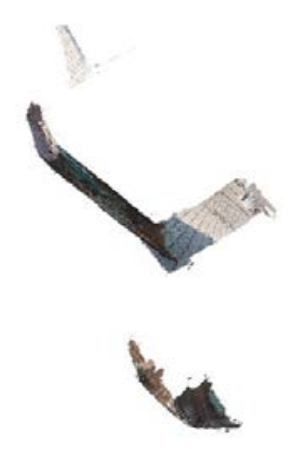


The winged Wrinkled is a flying territory that transmuted for years for those who watched it from the ground. The city hided in its funneling streetscapes the witnessing of a rounded Earth. To the North, Wrinkled courteously announced its intentions by drawing lines of expression. Its silhouette swayed from frown to marionette lines when they depicted focus or happiness, respectively. To the South, the city was more dynamic depicting through repetition barcodes and crow`s feet. At both hemispheres, though, the rumors speculated on Wrinkled bringing death and doom from the world's end. They also watched the passage of Wrinkled from the ground as a miraculous transmutation. A city who had flew far beyond any human reach. For Wrinkled inhabitants, though, just one more seasonal migration.

Nowadays, it still guards some quality from the unknown it inherited for thousands of years. Its lines of expression still disperse and announce the hidden patterns of changing nature. 
6.9 City and names

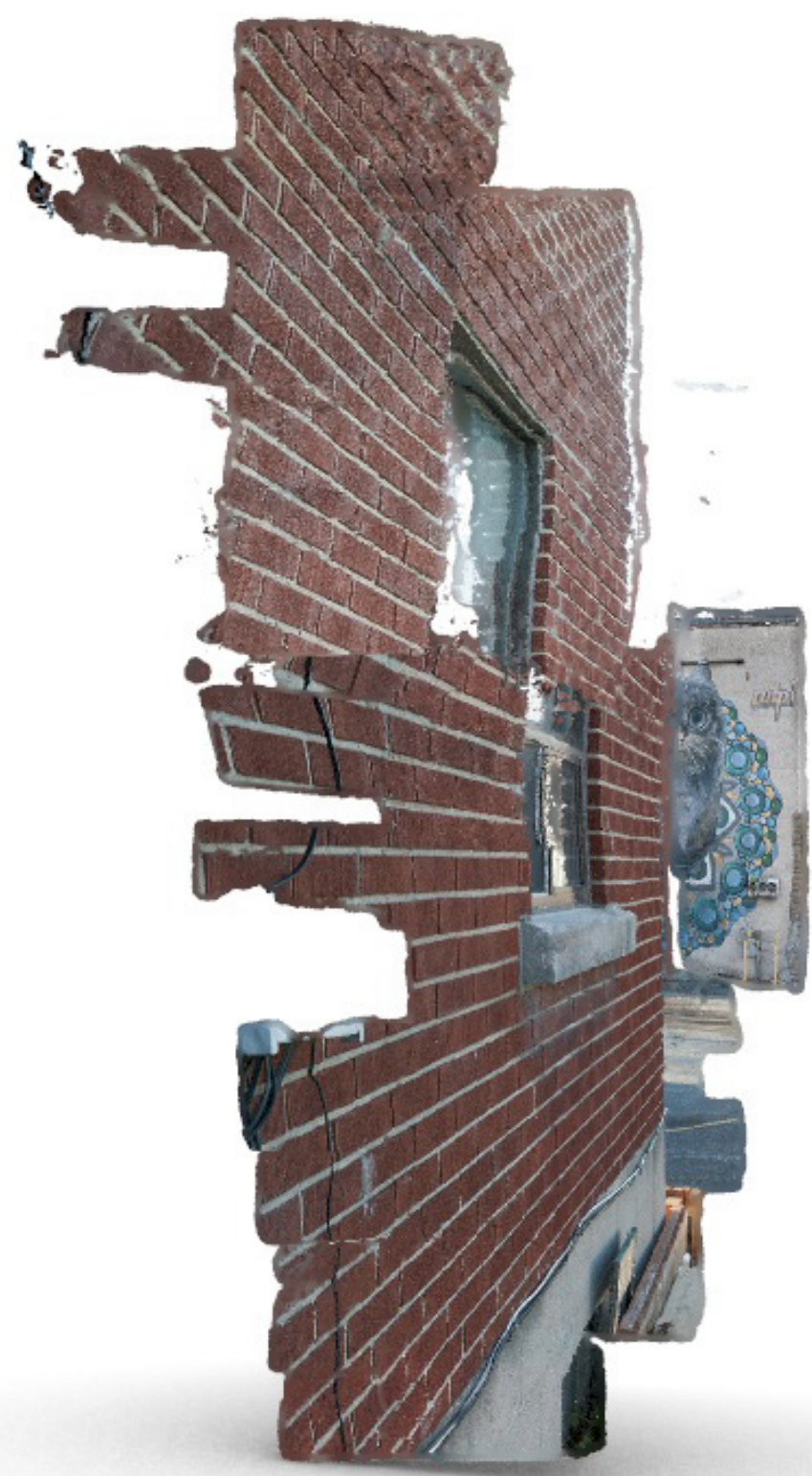




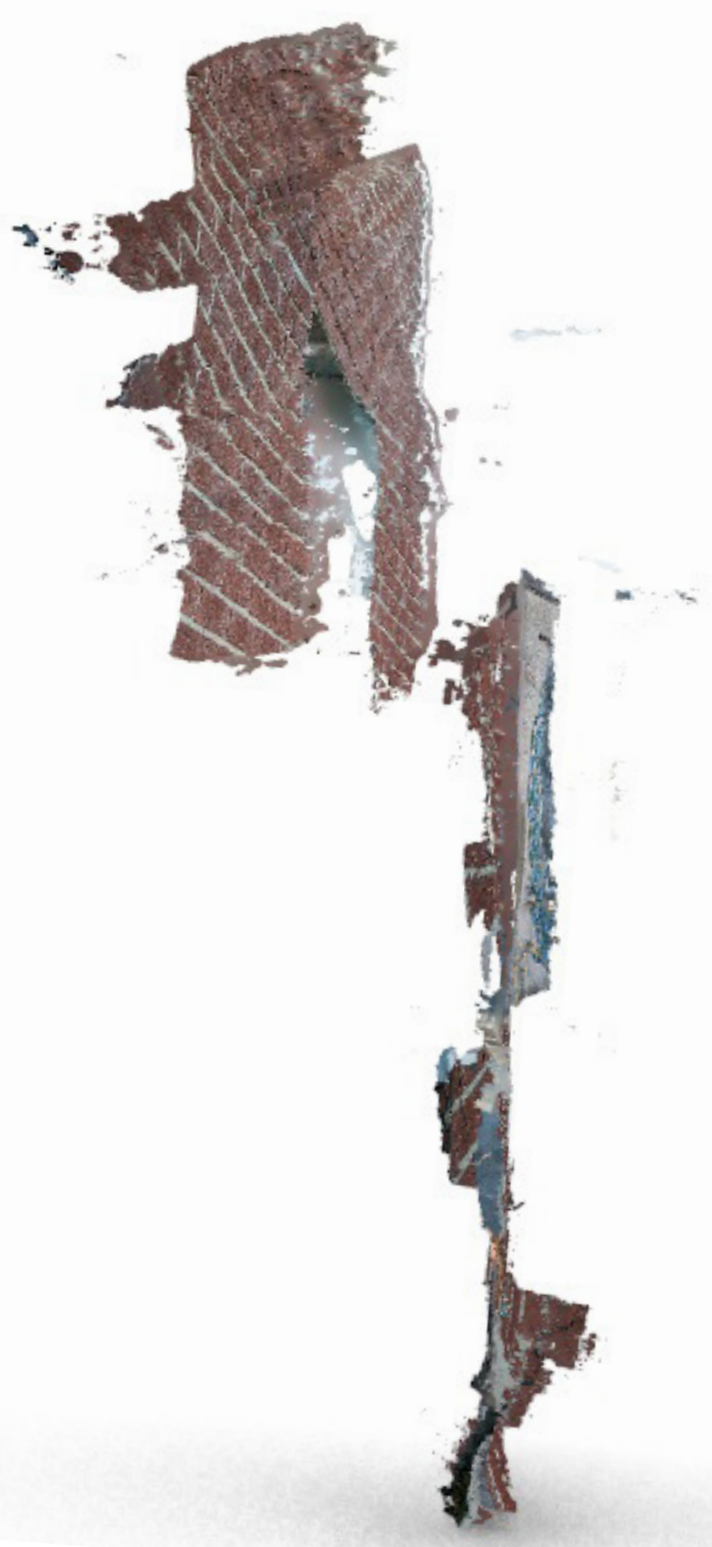


In a city where nobody can name things you would be forever curious. This is a place like Depth·less, a flattened territory without names. In this city there is no behind, or above, or anything that requires depth - thoughts? Everything coexists in the same plane. In fact, Depth-less is a post-traumatic place after curiosity killed the cat. It killed it because the cat would not hide behind the wall to watch it. No depth, no behind. The consequences have been quite dramatic since curiosity needs names to be killed, for instance. Names that can name, entitle, enumerate, illustrate. Thus, within the illusion of permanent guess the mentalists established ASMR lands in Depth.less. With industrialization, tactile streetscapes for sleight of hands training and digital mazes for the escapists boomed. And so, this city became the land for illusion where nobody can possibly name things. 


$$
1 /
$$


Lamina is different from other cities because it is far beyond reach. It is sunk somewhere where darkness and silence patiently surround the changing that is the death. Somehow, the exact point where death and life intertwine happens to have this curious connection to liquid environments. The ocean, the sperm, the galaxy that is milky, and so on. The liquid is also a defy for gravity, and gravity grant us to the basic notions of this reality which are space and time. Thus, Lamina exists in the continuum of density. A place where gravity floats, and so we float, and therefore no space or time. There is where the other side of this trivial human dimension might be. A place where no space or time can bend existence. Neither consciousness travels through the breath of spoken language. Instead, it travels much like our braincells discharging information in the liquid of blood. I wonder that another reality might look a bit like Lamina.

The cityscape is like one that segments the water into drops of water, just like leaves in the rain. If death and life have to deal with fluids, then the space that contains them must masters fluidity. Is there even such an abrupt thing as life and death? Or perhaps, it just changes from falling to dropping? 
6.11 City and the sky

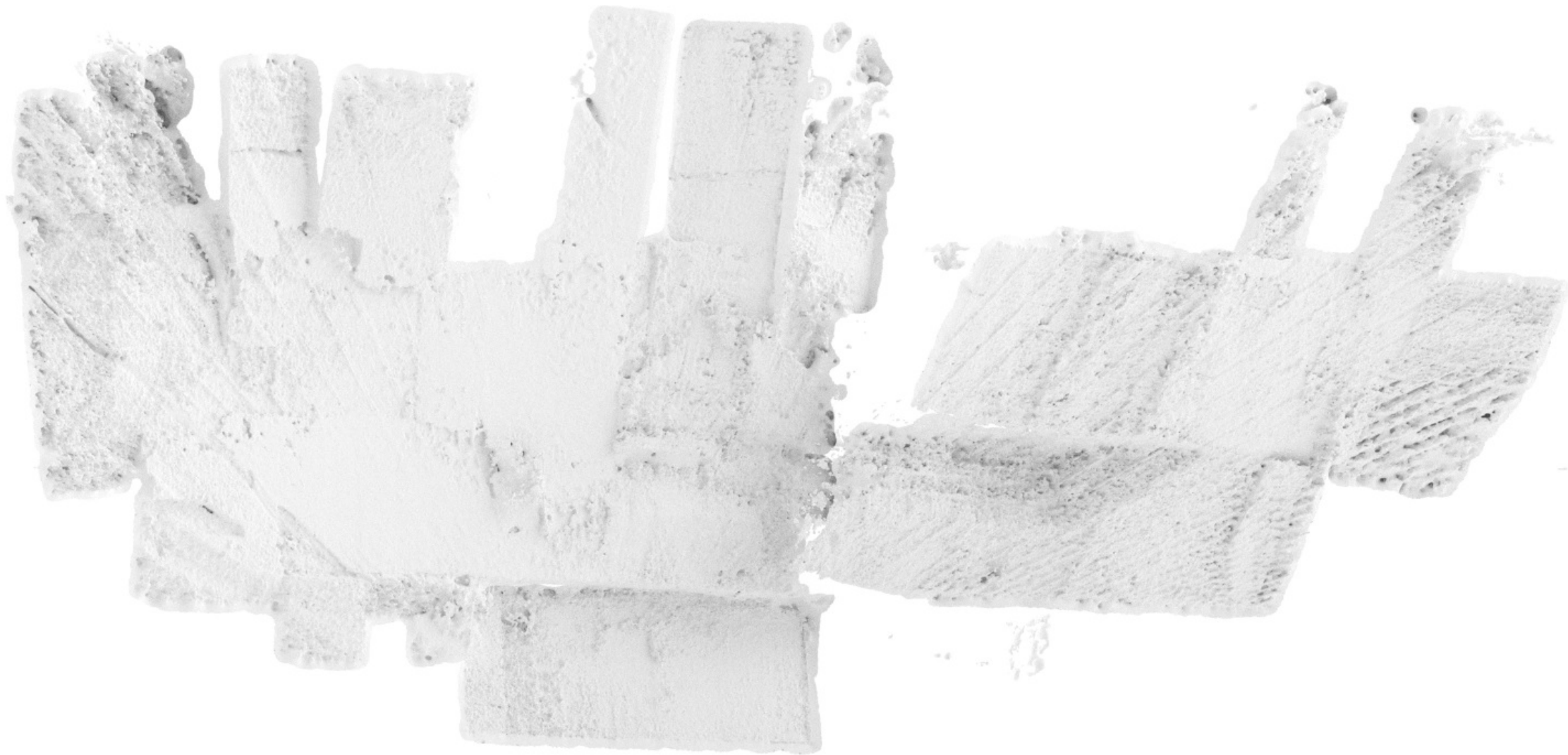


Everybody speculates on Cumulus. You might hear foreigners speaking of it, pointing at it, and they wonder and announce it. Cumulus slowly responds to it. It might be affirmative to the speculation or respond completely different. It likes to challenge curiosity but will take time to reveal its sarcasm. The unpredictability is its most notable feature. Its currency is density. Sometimes so light that its streets are invisibly wandering in the guess that evaporates. At other times, it is more like an angry aggregate, so dense that Cumulus just cannot hold it to itself and loses its houses in the precipitation. They all know, though, that it is a cycle and eventually it returns.

Its inhabitants love the Sun, and they often create ludic giants to march together. These figures overlap each other, or even cast shadow one onto another. The foreigners cannot tell, but they march, at a rigorous cadence. On the right, the city displays ships that are about to detach from the aggregate in another slow-motion journey of divination. There is one neighborhood where people masters the colors -- cerulean blue, ultramarine, mauve, alizarin crimson, and payne`s grey. Another one is for the sculptors where they gauge, soften and mediate values. A bit closer and you will see that moistened houses and buckled-proof paving build the ground and carefully animate the streetscape. 


\section{Conclusion}

This thesis imploded the bi-dimensional portrayal of street art photographs into a collection of three-dimensional universes. Thus, it offered alternative ways of experiencing street art. These new frames diversify the lexicon from generic frames -- a photograph or the often-frontal viewing of a mural in the streetscape - into frames that explore the subjectivity of the spectator. The visual information painted onto these walls are powerful enough to resignify the new visual imagery which it occupies. Altogether, the painted birds, eagles and cats helped to unfold the hidden simultaneities and adventures within the streetscape. This thesis sought to expand the visual vocabulary of the streetscape since it unveiled invisible urban phenomena through photogrammetry. It stemmed from an investigation of street art which departed from heritage guidelines and architecture as seen through the eyes of a photographer and photogrammetrist.

This research was not invested in capturing reality, but rather to unfold the invisible terrains within reality. Therefore, an alternative workflow to Photogrammetry`s accepted method was proposed. Its greatest change relies in motion. It introduced the stiff positioning of the photographer as opposed to the regular structured motion around the object. Respecting this single eye-ball positioning forced the software to reimagine alternative systems of coordination. Nonetheless, the motionless capture removes the system of references around the object which ultimately allow the computer to process the object in comparison to another. This method unveiled new terrains that are most like deliberate accidents, awakening dreams in those who see it. To some extent, I like to compare the reading of them to the moment when we lay down on the ground and look up to the skies while negotiating with a close friend the most accurate guess of what figure the cloud depicts. Elsewhere, this reasoning is similar to Da Vinci's faith in stains on the walls:

"If you look upon an old wall covered with dirt, or the odd appearance of some streaked stones, you may discover several things like landscapes, battles, clouds, uncommon attitudes, humorous faces, draperies, etc. Out of this confused mass of objects, the mind will be furnished with 
an abundance of designs and subjects perfectly new". ${ }^{52}$

The Glitch-Visible cities are my navigation through this visual imagery. Thus, it is figuratively my interpretation over the stain or the passing cloud. Altogether, they are my different ways of looking at cities while your eyes might see others. By fusing street art with architecture, this research was able to subvert even its underlying question: What if Architecture became Street Art? to which it responded through the Hidden City of EPAGRÝPNISI. If writers and street artists were to establish any territory, it would most likely be a camouflaged terrain much like EPAGRÝPNISI, silent yet transformative.

52 Christopher P Jones, "Why I Let Chance Into My Life," Medium (Thinksheet, November 26, 2019), https://medium.com/ thinksheet/why-i-let-chance-into-my-life-e1055187d01a. 


\section{Bibliography}

BBC A Brief History of Graffiti. BBC A Brief History of Graffiti. Great Britain: BBC, 2015. https://www.youtube.com/ watch?v=haVjpXGTJ-I\&feature=emb_logo.

Barthel, Jennifer. "Perceptions of Graffiti in Ottawa : an Ethnographic Study of an Urban Landscape ." Thesis (M.A.) - Carleton University, 2002., 2002. Print.

Barthes, Roland. Camera lucida : reflections on photography New York: Hill and Wang, 1981.

Calvino, Italo. Invisible cities [1st ed.]. New York: Harcourt Brace Jovanovich, 1974.

Calvino, Italo. The uses of literature: essays 1st U.S. ed. San Diego: Harcourt Brace Jovanovich, 1986.

Chang, Vanessa. "Animating the City: Street Art, Blu and the Poetics of Visual Encounter." Animation : an interdisciplinary journal 8, no. 3 (2013): 215-233.

"Design Activism: Dilip Da Cunha \&amp; Anuradha Mathur." Australian Design Review, November 23, 2016. https:// www.australiandesignreview.com/architecture/designactivism-dilip-da-cunha-anuradha-mathur/.

Duncan, Dennis. The Oulipo and Modern Thought First edition. Oxford: Oxford University Press, 2019.

Eckhard, Petra. "Urban Figures, Common Ground: JR and the
Cultural Practices of Perception." European journal of American studies 10, no. 3 (December 31, 2015).

Ferdman, Bertie. "Urban Dramaturgy: The Global Art Project of JR." PAJ (Baltimore, Md.) 34, no. 3 (September 1, 2012): 12-26.

Hansen, Susan. "Banksy's Subversive Gift: A Socio-Moral Test Case for the Safeguarding of Street Art." City (London, England) 22, no. 2 (March 4, 2018): 285-297.

Jones, Christopher P. "Why I Let Chance Into My Life." Medium. Thinksheet, November 26, 2019. https://medium.com /thinksheet/why-i-let-chance-into-my-life-e1055187d01a.

Judson, Derek R. "Beyond Space? : Exploring the Temporality of Architecture ." Thesis (M.Arch.) - Carleton University, 2011. Print.

Kalman, Harold. Heritage Planning : Principles and Process New York, New York ;: Routledge, 2015.

Logan, William. "Burra 25: The Australian ICOMOS Charter of Places of Cultural Significance (The Burra Charter)."Historic Environment 2004: 1,.

Luhmann, Thomas, Jan Boehm, Stephen Kyle, and Stuart Robson. Close-Range Photogrammetry and 3D Imaging 2nd ed. Berlin ;: De Gruyter,, 2013.

McCarthy, John. "Multi-Image Photogrammetry as a Practical Tool for Cultural Heritage Survey and Community Engagement." 
Journal of archaeological science 43 (2014): 175-185.

Merrill, Samuel. "Buffing and Buffering Blu: The Societal Performance of Street Art, Heritage Erasure and Digital Preservation in Berlin." International journal of heritage studies : IJHS ahead-of-print, no. ahead-of-print (n.d.): $1-16$.

Merrill, Samuel. "Keeping It Real? Subcultural Graffiti, Street Art, Heritage and Authenticity." International journal of heritage studies : IJHS 21, no. 4 (April 21, 2015): 369-389.

Modena, Letizia. Italo Calvino's Architecture of Lightness: The Utopian Imagination in An Age of Urban Crisis. Vol. 17. London: Routledge, 2011.

Neighbourhood Plan Hintonburg and Mechanicsville. Ottawa: City of Ottawa, 2010.

Sarkis, Hashim, Roi Salgueiro Barrio, and Gabriel Kozlowski. The World as an Architectural Project. Cambridge, MA: The MIT Press, 2019.

Spiller, Neil. Architecture and Surrealism a Blistering Romance. London: Thames \& Hudson, 2016.

The Burra Charter: The Australia ICOMOS Charter for Places of Cultural Significance, 2013.

Wacławek, Anna. Graffiti and Street Art. London ;: Thames \& Hudson, 2011. 